\title{
Conflict monitoring and the affective-signaling hypothesis-An integrative review
}

\author{
David Dignath $^{1} \cdot$ Andreas B. Eder $^{2} \cdot$ Marco Steinhauser $^{3} \cdot$ Andrea Kiesel $^{1}$
}

Published online: 2 January 2020

(C) The Psychonomic Society, Inc. 2020

\begin{abstract}
Conflict-monitoring theory proposes that conflict between incompatible responses is registered by a dedicated monitoring system, and that this conflict signal triggers changes of attentional filters and adapts control processes according to the current task demands. Extending the conflict-monitoring theory, it has been suggested that conflict elicits a negative affective reaction, and that it is this affective signal that is monitored and then triggers control adaptation. This review article summarizes research on a potential signaling function of affect for cognitive control. First, we provide an overview of the conflict-monitoring theory, discuss neurophysiological and behavioral markers of monitoring and control adaptation, and introduce the affective-signaling hypothesis. In a second part, we review relevant studies that address the questions of (i) whether conflict elicits negative affect, (ii) whether negative affect is monitored, and (iii) whether affect modulates control. In sum, the reviewed literature supports the claim that conflict and errors trigger negative affect and provides some support for the claim that affect modulates control. However, studies on the monitoring of negative affect and the influence of phasic affect on control are ambiguous. On the basis of these findings, in a third part, we critically reassess the affective-signaling hypothesis, discuss relevant challenges to this account, and suggest future research strategies.
\end{abstract}

Keywords Cognitive control · Conflict adaptation · Cognition-emotion interaction · Sequential congruency effect · Gratton effect $\cdot$ Affect

Dual-system frameworks in psychology often portrayed affective processes as opposing forces to willful behavior: During goal pursuit, people must often resist distracting behavioral impulses associated with affective states (Metcalfe \& Mischel, 1999; Muraven \& Baumeister, 2000; Strack \& Deutsch, 2004). However, more recent research has highlighted a functional interaction between cognitive control and affect (Goschke \& Bolte, 2014; Pessoa, 2008). For instance, affective states (i.e., valence and arousal; see Barrett \&

This research was supported by grants within the Priority Program SPP 1772 from the German Research Foundation (Deutsche Forschungsgemeinschaft, DFG): grant no. DI 2126/1-2 to D.D., grant no. STE $1708 / 4-2$ to M.S., and grant no. KI1388/8-2 to A.K.

David Dignath

david.dignath@psychologie.uni-freiburg.de

University of Freiburg, Freiburg im Breisgau, Germany

University of Würzburg, Würzburg, Germany

3 Catholic University of Eichstätt-Ingolstadt, Eichstätt, Germany
Russell, 1999) convey important information about our inner life and have an important signaling function for many cognitive operations (Damasio, 1996; Frijda, 1988; Oatley \& Johnson-Laird, 1987). This article is concerned with the particular signaling function of affect for cognitive control.

Research on cognitive control described a dedicated neurocognitive system that monitors the planning, initiation, and execution of actions. According to the conflictmonitoring theory, performance monitoring serves to inform and change future behavior (Botvinick, Braver, Barch, Carter, $\&$ Cohen, 2001). Although this was initially envisaged as a cognitive theory, recent proposals have suggested that conflict between mutually exclusive responses triggers a negative affective reaction, and that this affective response to conflict is what is registered by the performance-monitoring system. Upon registration, the affective reaction triggers adaptations of attention and performance that aim to attenuate future conflict (Botvinick, 2007; Dreisbach \& Fischer, 2015; Inzlicht, Bartholow, \& Hirsh, 2015; van Steenbergen, 2015). In the following sections, we refer to this set of theoretical positions as the affective-signaling hypothesis. In short, it assumes a 
bidirectional link between affect and control: Affect is not only the output of control-related processes (i.e., conflict elicits negative affect); it can also serve as input for controlrelated processes (i.e., negative affect as a learning signal).

Interestingly, the affective-signaling hypothesis suggests a novel perspective on the interaction between affect and cognitive control. Affect can be understood as the fuel and driving force of control operations whereas (cognitive) control operations can be understood in a more general framework of affect-regulation. This potential to reconcile cognitive and affective operations into a common mechanism makes the affective-signaling hypothesis particularly attractive.

Research on the interplay between affect and cognitive control expanded rapidly in the last decade (cf. Okon-Singer, Hendler, Pessoa, \& Shackman, 2015). ${ }^{1}$ Regarding the affective-signaling hypothesis, previous work focused on neuroanatomical (Shackman et al., 2011), psychophysiological (Saunders, Lin, Milyavskaya, \& Inzlicht, 2017), and behavioral (Dreisbach \& Fischer, 2012, 2015, 2016) aspects.The present article complements previous work by providing a comprehensive review of relevant research with the aim to evaluate the currently available evidence related to the affective-signaling hypothesis. Following recent theorizing (Dreisbach \& Fischer, 2012; van Steenbergen, 2015), the present article integrates the literature from different domains according to the particular theoretical perspective of the conflictmonitoring theory (for a different view; see Notebaert \& Verguts, 2008). Conflict monitoring offers a detailed and mechanistic description of cognitive control, which allows a close matching of affective processes on control mechanisms. Furthermore, conflict-monitoring theory explains response conflict and error processing in a unitary model. This allows an integration of empirical work that focused either on conflict or errors.

The structure of the argument in this article includes three parts. The first section introduces the conflict-monitoring theory with respect to its two central components-performance monitoring and control adaptation - and derives a process model of the affective-signaling hypothesis within this model. In the second part, we review evidence relevant to the affective-signaling hypothesis. Three lines of research are reviewed: (i) behavioral and physiological evidence showing that conflict and errors elicit negative affect; (ii) neurophysiological evidence showing that correlational and experimental manipulations of affect influence monitoring of conflict and errors; and (iii) behavioral evidence showing that correlational and experimental manipulations of affect influence adaptation of control to conflict and errors. The third part provides a

\footnotetext{
${ }^{1}$ A Web of Science search, using the terms "TS=((cognitive control) AND (affect* OR emotion*)) AND SU=(Psychology OR Neurosciences \& Neurology OR Behavioral Sciences) AND PY=(2000-2018)," showed that the number of publications on "cognitive control and affect" increased from 279 in the year 2000 to 2,130 in the year 2018 .
}

critical discussion of the affective-signaling idea and suggestions for future research.

\section{Conflict-monitoring theory}

Conflict between temporally co-activated, but mutually exclusive actions is a fundamental challenge for action control, and it has been suggested that control mechanisms are needed to prevent and/or resolve conflict (see, e.g., Allport, 1987; Botvinick et al., 2001; Miller \& Cohen, 2001; Norman \& Shallice, 1986). An influential model that accounts for such control mechanisms is the conflict-monitoring theory. Here, conflict is registered and used to change control settings. Importantly, the conflict-monitoring theory views errors as special case of conflict. Whereas conflict in correct trials should be highest before response execution (i.e., before the correct response is selected), conflict in trials with incorrect responses should be highest after response execution, because of the conflict between the incorrect response and a tendency to correct the produced response (cf. Yeung, Botvinick, \& Cohen, 2004).

Conflict monitoring entails two components: (1) a monitoring component that evaluates the degree of conflict and (2) a control adaptation component that adjusts attentional filters to the current task demands. Concerning neural implementation, monitoring has been associated to the dorsal regions of the anterior cingulate cortex (dACC; Botvinick, Nystrom, Fissel, Carter, \& Cohen, 1999; Carter et al., 1998), whereas control adaptation has been linked to activity in the dorsolateral prefrontal cortex (DLPFC), which is associated with a sharpening of relevant task representations (Kerns et al., 2004). These two control components complement each other and form a control loop: The conflict signal triggers control adaptation by means of a learning signal that specifies a need for changes in attention. These changes in attention, in turn, lead to a subsequent reduction of conflict. In what follows, we present a selective review of evidence for both components.

\section{Performance monitoring}

One way to probe the monitoring component is the usage of scalp-recorded electrophysiological potentials. For instance, the $\mathrm{N} 2$ component has been described as a negative deflection in the electroencephalogram (EEG) that peaks around $250 \mathrm{~ms}$ after stimulus onset and is larger after the presentation of a conflicting stimuli (Kopp, Rist, \& Mattler, 1996; Yeung et al., 2004; see also Liotti, Woldorff, Perez, \& Mayberg, 2000, for the Stroop task). Furthermore, errors are reflected in the EEG by the error-related negativity (ERN; see Yeung et al., 2004; for alternative accounts, see Alexander \& Brown, 2010; Falkenstein, Hoormann, Christ, \& Hohnsbein, 2000; Holroyd \& Coles, 2002; Nieuwenhuis, Ridderinkhof, Blom, 
Band, \& Kok, 2001). The ERN peaks around $100 \mathrm{~ms}$ after an incorrect response (Falkenstein, Hohnsbein, Hoormann, \& Blanke, 1991; Gehring, Coles, Meyer, \& Donchin, 1990; see Gehring, Liu, Orr, \& Carp, 2012, for a review); it is sensitive to the frequency of errors (Holroyd \& Coles, 2002), the motivational significance (Hajcak, Moser, Yeung, \& Simons, 2005) and the type of error (Bernstein, Scheffers, \& Coles, 1995; Maier \& Steinhauser, 2013). In line with the view that errors reflect a special case of conflict, dipole source location and $\mathrm{FMRI}$ studies identified the $\mathrm{dACC}$ and the premotor supplementary areas as the neural generators of the N2 and the ERN response (Carter et al., 1998; Dehaene, Posner, \& Tucker, 1994; Holroyd et al., 2004; Keil, Weisz, PaulJordanov, \& Wienbruch, 2010; Miltner et al., 2003; Ridderinkhof, Ullsperger, Crone, \& Nieuwenhuis, 2004).

\section{Control adaptation}

Studies on performance monitoring are complemented by behavioral and neuroimaging studies on control adaptation. Conflict adaptation is indexed by the sequential congruency effect, which describes a modulation of the congruency effect as a function of the level of congruency of the preceding trial. In particular, congruency effects in the current trial $N$ are reduced after incongruent (relative to congruent) trials $N-1$. The sequential congruency effect has been observed in a variety of response interference paradigms (flanker: Gratton, Coles, \& Donchin, 1992; Simon: Fischer, Plessow, Kunde, \& Kiesel, 2010; Stroop: Kerns et al., 2004; priming tasks: Kunde \& Wühr, 2006; go/no-go task: Smith, Smith, Provost, \& Heathcote, 2010; task switching: Kiesel, Wendt, \& Peters, 2007)

Studies showed that sequential congruency effects result from enhanced perceptual processing of the relevant stimulus dimension (e.g., Egner \& Hirsch, 2005; Nigbur, Schneider, Sommer, Dimigen, \& Stürmer, 2015) and weakening of automatic response activation by the irrelevant stimulus dimension (Stürmer, Leuthold, Soetens, Schröter, \& Sommer, 2002; Stürmer, Redlich, Irlbacher, \& Brandt, 2007). Accordingly, the sequential congruency effect corresponds to an adjustment of attentional filtering efficacy and indexes control adaption: When an incongruent stimulus is encountered, conflict is detected and triggers an up-regulation of attentional focus that facilitates behavioral performance.

\section{The control loop: From performance monitoring to control adaptation}

In theory, the idea that monitoring informs control adaptation has two implications: First, the monitoring signal provides a means to gauge the need for control. Thus, the strength of conflict should scale with the magnitude of control adaption. This prediction is supported by studies showing that increased monitoring of conflict in the preceding trial (as indicated by the N2) is accompanied by an increased magnitude of sequential congruency effect (Forster, Carter, Cohen, \& Cho, 2010; Wendt, Kiesel, Gehringswald, Purmann, \& Fischer, 2014; but see Egner, Jamieson, \& Gruzelier, 2005). Furthermore, conflict-related activity in the dACC during the preceding trial predicts the size of the sequential congruency effect in the subsequent trial (Kerns et al., 2004), and lesions of the dACC impair the sequential congruency effect (di Pellegrino, Ciaramelli, \& Làdavas, 2007; Tolomeo et al., 2016; but see Fellows \& Farah, 2005; Vendrell et al., 1995). The second assumption holds that monitoring of conflict is not identical with control adaptation in terms of neural localization. This prediction is supported by studies showing that the size of the sequential congruency effect correlates with activity in the DLPFC but not in the dACC (Egner \& Hirsch, 2005; Kerns et al., 2004). Further support has come from virtual lesion studies showing that transcranial direct current stimulation to the dACC and SMA (supplementary motor area) increased error monitoring (as indexed by the ERN; Reinhart \& Woodmann, 2014), whereas stimulation of the DLPFC enhanced the magnitude of the sequential congruency effect (Gbadeyan, McMahon, Steinhauser, \& Meinzer, 2016).

\section{An affective interpretation of conflict-The affective-signaling hypothesis}

The original version of conflict monitoring was introduced as a theory of cognitive control. However, authors endorsed the idea that conflict and error monitoring are based on affective processes (e.g., Luu, Collins, \& Tucker, 2000). This inference is motivated by neurophysiological studies showing that the dACC is not exclusively activated by conflict and errors, but also serves as a central hub for information processing related to emotions and in particular negative affect (Kober et al., 2008; Papez, 1937), pain (Rainville, Duncan, Price, Carrier, \& Bushnell, 1997), and social distress (Eisenberger, Lieberman, \& Williams, 2003; for a meta-analysis, see Shackman et al., 2011). Furthermore, evidence from local field potentials during intracranial recording showed selective coupling between dACC and the amygdala, suggesting that the dACC is part of a broader affective network in the brain (Pourtois et al., 2010; see also Kunishio \& Haber, 1994). Lesions of the dACC also cause severe deficits in the recognition of negative emotions (Tolomeo et al., 2016) and in motivated action, despite intact motoric abilities (akinetic mutism; see Németh, Hegedüs, \& Molnâr, 1988). Together, this body of evidence suggests that neuronal correlates of performance monitoring and affective processing overlap substantially.

In line with an affective interpretation of dACC activity, it has been suggested that the ERN reflects an affective response to errors (Pailing, Segalowitz, Dywan, \& Davies, 2002; Luu \& 
Pederson, 2004; Yeung et al., 2004). Gehring and Willoughby (2002) proposed that "the ERN might reflect an appraisal of the motivational or affective impact of the error rather than a computation related to detecting the error or response conflict" (p. 2281). The hypothesis that the monitoring system registers affective reactions to conflict and error was supported by studies showing that both are evaluated negatively (e.g., Aarts, De Houwer, \& Pourtois, 2012; Dreisbach \& Fischer, 2012; Hajcak \& Foti, 2008). Furthermore, other research found that experimentally induced positive affect reduced control adaptation (indexed by the sequential congruency effect), presumably because it weakened the negative affective signal driving control adaptation (e.g., van Steenbergen, Band, \& Hommel, 2009).

Based on these observations, researchers proposed an affective-control framework that ascribes a central role of conflict- or error-triggered affect for control (e.g., the "conflicts as aversive signals framework"; Dreisbach \& Fischer, 2015; see also Inzlicht et al., 2015; Saunders et al., 2017; van Steenbergen, 2015). For instance, it has been suggested that "cognitive control . . . is dependent on emotion" (Inzlicht et al., 2015, p. 126), and that "conflict adaptation . . . might actually represent an instantiation of affect regulation" (Dreisbach \& Fischer, 2015, p. 256). More specifically, these accounts assumed that conflict or errors elicit an affective reaction (we will refer to this assumption as the conflict affect link). Subsequently, performance monitoring does not register conflicts and errors alone, but importantly, it detects also the affective reaction to these events (we refer to this assumption as the affect monitoring link). And finally, this affective response to conflict and errors, rather than conflict and errors per se, drives changes in control adaptation: An affective learning signal causes an updating of relevant task representations and is a direct function of the registered affective response (we refer to this assumption as the affect control link). The last claim assumes that negative affect elicited through conflict/errors is not only a byproduct of conflict processing but rather causal for control adaptation. We will refer to this set of propositions as the affective-signaling hypothesis (see Fig. 1 for an illustration). In the next part of this article, we will review evidence for each of these claims.

\section{Evidence for the affective-signaling hypothesis}

The following literature review is structured into three sections. In the first section, we review evidence for the assumption that conflict or errors trigger an affective response (i.e., the conflict affect link). Here, studies are discussed that probed participants' explicit, implicit, and physiological valuation of conflict and errors. In the second section, we review evidence for the assumption that the monitoring process is influenced by affective states (i.e., the affect $\boldsymbol{D}$ monitoring link). This section reviews studies that investigated the effects of affective states on ERN or N2 responses. In the third section, we review evidence for the assumption that control adaptation is triggered by negative affective states (i.e., the affect - control link). This section describes studies that have investigated the effects of affective states on the sequential congruency effect.

\section{Inclusion criterion for the literature review}

Before we begin reviewing empirical evidence, we first narrow down the scope of the reviewed research.

Selection of conflict tasks Because the notion of conflict is central to conflict monitoring and affective signaling, only studies that employed response interference tasks were considered (i.e., flanker, Stroop, Simon, the grasp compatibility effect, go/no-go tasks, stop-signal tasks, and task switching ${ }^{2}$ ). Other paradigms that measure further aspects of cognitive control like working memory updating and maintenance (e.g., task-rule switching, the AX-CPT task, span tasks, or $\mathrm{N}$-back tasks) are not reviewed here. We also did not include studies on the emotional interference Stroop task, because affective information is part of the relevant response set (Etkin, Egner, Peraza, Kandel, \& Hirsch, 2006) and we also excluded studies on the "typical" emotional Stroop task, because this effect has been attributed to an unspecific slowing (Algom, Chajut, \& Lev, 2004).

Selection of dependent variables All included task protocols elicit response conflict that can be measured with the N2 or ERN as markers of performance monitoring and results in compensatory changes in attention that can be measured with the sequential congruency effect as a marker of control adaptation. The feedback-related negativity (FRN) is not considered, because it is beyond the scope of the conflict-monitoring theory. Posterror slowing is not discussed, because its relation to monitoring and cognitive control is unclear (for discussions, see Danielmeier \& Ullsperger, 2011; Steinhauser, Ernst, \& Ibald, 2017). For measures of affect, we considered both explicit (e.g., ratings) and implicit (e.g., affective priming) behavioral measures and physiological markers of valence and arousal (see Table 1 for details).

Selection of affective manipulations We define "affect" as a psychophysiological construct that is characterized by (i) the pleasantness or hedonic tone of an episode (valence), and (ii) a

\footnotetext{
${ }^{2}$ Only studies that have used bivalent stimuli that allow for responsecongruency effects were included. Typically, response-congruency effects are larger on task alternation than on task repetition trials, and therefore contribute significantly to switch costs (Goschke, 2000).
} 


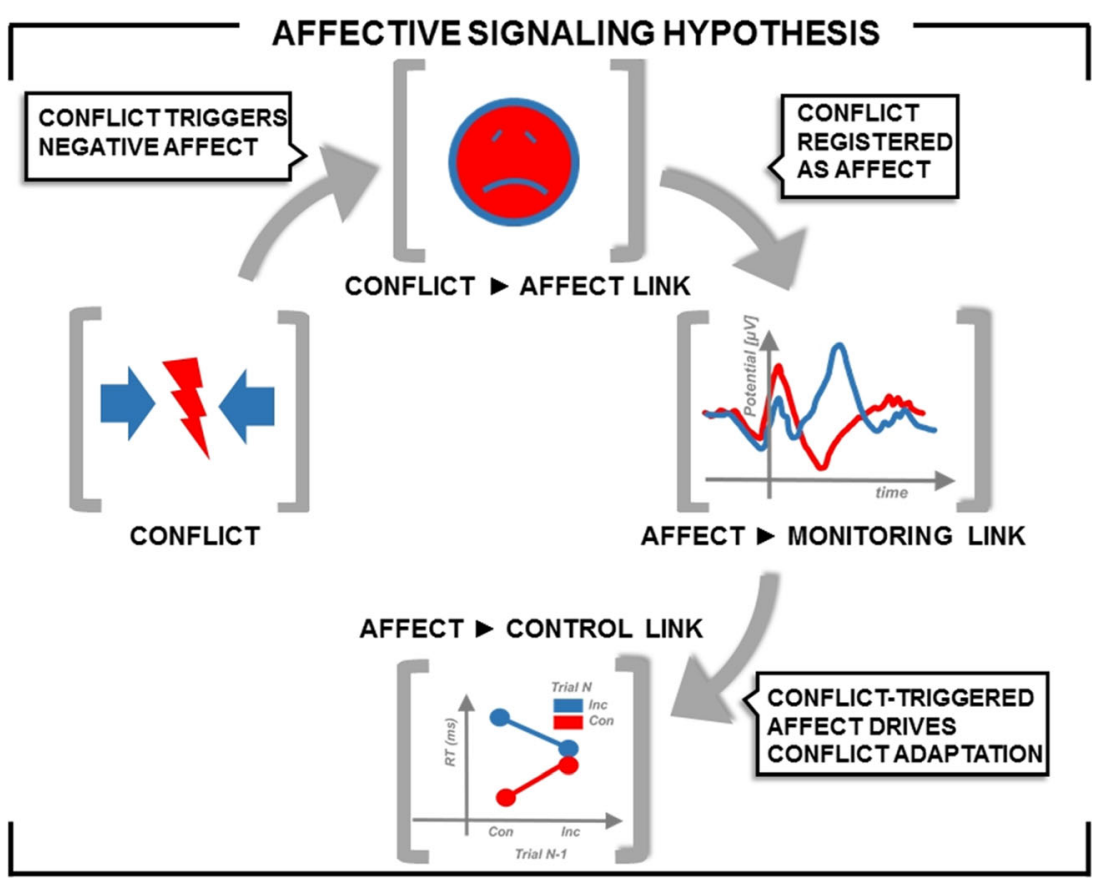

Fig. 1 Schematic illustration of the affective-signaling hypothesis. Conflict between responses (left) triggers a brief negative affective reaction (top: I. the conflict affect link). The review describes several dependent measures that assess the affective consequences of conflict and errors. This conflict/error-triggered affect is supposed to be detected by a monitoring system (right: II. the affect $>$ monitoring link; the N2 [blue in online, color figure] and the error-related negativity [ERN; red online] provide online measures of conflict/error monitoring). Subsequently, this signal is used for adaptive changes in attention and performance (bottom: III. the affect $\boldsymbol{~ c o n t r o l ~ l i n k ; ~ t h e ~ s e q u e n t i a l ~ c o n - ~}$ gruency effect provides a measure of adaptation to conflict). As a consequence, conflict following previous conflict is reduced, and the resulting affective responses are less negative potential for (physiological) mobilization or energization (arousal) (Barrett \& Russell, 1999). Affective states differ in duration and can range from brief affective sensations (phasic) to relatively long-lasting moods (tonic). We will refer to manipulations that change affect on a trial-by-trial basis as phasic affect, because these affective reactions are likely to decay in the order of seconds (e.g., Codispoti, Bradley, \& Lang, 2001; Cuthbert, Schupp, Bradley, Birbaumer, \& Lang, 2000). In contrast, we refer to manipulations that induce more enduring affective states as tonic affect.

Regarding phasic manipulations of affect, studies were considered in which presentations of affective stimuli were not contingent upon behavioral performance. If studies compared performance contingent and non-contingent affect presentation across groups, we considered only data of the performance non-contingent group (e.g., Braem et al., 2013; Yamaguchi \& Nishimira, 2019). The distinction between affective states that are contingent or independent from behavioral performance is important, because research has shown that stimuli acquire reinforcing properties when they signal correct performance, which strengthens the active attentional set (for a discussion, see Chelazzi, Perlato, Santandrea, \& Della Libera, 2013). In particular, it has been argued that control adaptation in terms of the sequential congruency effect is increased by presentations of performance-contingent affective stimuli (see Braem, Verguts, Roggeman, \& Notebaert, 2012; Braem et al., 2013; Yang \& Pourois, 2018).

Affective states are also closely linked to motivational tendencies of approach and avoidance. Although positive affect was typically linked to approach motivation, and negative affect to avoidance, one should be cautious in inferring motivational states from affective states, because unpleasant states can also evoke motivations to approach (e.g., aggressive behavior; see Berkowitz \& Harmon-Jones, 2004) and behavioral approach could subserve prevention goals (Higgins, 1997).

Literature search strategy We retrieved studies published in peer-review journals in English by conducting database searches through Web of Science and Google Scholar (search period 2000-2018, for the research areas Psychology, Behavioral Sciences and Neuroscience, and Neurology) separately for each of the three sections described above. In addition, we carefully examined the reference sections of qualifying articles and previous literature reviews for citations and searches on the names of frequently occurring authors. When available, we will refer to meta-analysis or review articles of specific research areas. For brevity, this literature will not be reviewed again (but see Tables 1-3). 
Table 1 Data from studies that have investigated the affective consequences of conflict and errors (the conflict affect link)

\begin{tabular}{llll}
\hline Reference & Task & $\begin{array}{l}\text { Response to } \\
\text { Conflict }\end{array}$ & DV Affect
\end{tabular}

\begin{tabular}{|c|c|c|c|c|}
\hline Aarts, et al., 2012 & go/no-go & yes & affective priming & error: $\downarrow$ RT (neg) \\
\hline Aarts, et al., 2013 & go/no-go & yes & affective priming & error: $\downarrow$ RT (neg) \\
\hline Botvinick \& Rosen, 2009, Exp. 1 & task switching & yes & task choice & context (high inc): $\downarrow$ choices \& $\uparrow$ SCR \\
\hline Botvinick \& Rosen, 2009, Exp. 2 & task switching & yes & task choice & context (high inc): $\downarrow$ choices $\& \uparrow$ SCR \\
\hline Botvinick et al., 2009 & task switching & yes & task choice & context (high inc): $\downarrow$ choices \\
\hline Braem et al., 2017 & task switching & yes & fMRI & inc: $\downarrow$ ACC response to negative pictures \\
\hline Brouillet et al., 2011 & grasp-CE & no & affective priming & inc: $\downarrow$ RT (neg) \\
\hline Buttaccio \& Hahn, 2010 & go/no-go & yes & rating of target & NoGo: $\uparrow$ rating (neg) \\
\hline Chetverikov et al., 2017 & flanker & yes & $\begin{array}{l}\text { rating of target \& } \\
\text { distractor }\end{array}$ & error: $\uparrow$ rating (neg); no inc-effect \\
\hline Damen et al., 2018, Exp. 1 & Stroop & no & AMP & inc: $\uparrow$ rating (neg) \\
\hline Damen et al., 2018, Exp. 2 & Stroop & no/yes & AMP & inc: $\uparrow$ rating (neg) for active and passive Stroop \\
\hline Damen et al., 2018, Exp. 3 & Stroop & no/yes & AMP & inc: $\uparrow$ rating (neg) for active and passive Stroop \\
\hline Damen et al., 2018, Exp. 4 & Stroop & no/yes & AMP & inc: $\uparrow$ rating (neg) for active and passive Stroop \\
\hline $\begin{array}{l}\text { De Saedeleer \& Pourtois, 2016, } \\
\text { Exp. } 1\end{array}$ & go/no-go & yes & affective priming & error: $\downarrow$ RT (neg) \\
\hline $\begin{array}{l}\text { De Saedeleer \& Pourtois, 2016, } \\
\text { Exp. } 2\end{array}$ & go/no-go & yes & affective priming & error: $\downarrow$ RT (neg) \\
\hline Desender et al., 2017, Exp. 1 & prime-target & yes & task choice & context (high inc): $\downarrow$ choices \\
\hline Desender et al., 2017, Exp. 2 & prime-target & yes & task choice & context (high inc): $\downarrow$ choices \\
\hline Desender et al., 2017, Exp. 3 & prime-target & yes & task choice & context (high inc): $\downarrow$ choices \\
\hline Dignath \& Eder, 2015, Exp. 1 & Stroop & no & approach avoidance task & inc: $\uparrow$ choices (avoidance) \\
\hline Dignath \& Eder, 2015, Exp. 2 & Stroop & no & approach avoidance task & inc: $\downarrow$ RT (avoidance) $\& \uparrow$ choices (avoidance) \\
\hline Dignath \& Eder, 2015, Exp. 3 & Stroop & no & approach avoidance task & inc: $\downarrow$ RT (avoidance) \& $\uparrow$ choices (avoidance) \\
\hline Dignath et al., 2015, Exp. 1 & Simon \& flanker & yes & task choice & inc: $\uparrow$ switchrate \\
\hline Dignath et al., 2015, Exp. 3 & Simon \& flanker & yes & task choice & inc: $\uparrow$ switchrate \\
\hline Doallo et al., 2012 & go/no-go & yes & rating of target & NoGo: $\downarrow$ rating (trust) \\
\hline Dreisbach \& Fischer, 2012 & Stroop & no & affective priming & inc: $\downarrow$ RT (neg) \\
\hline Dunn et al., 2018 & task switching & yes & task choice & context (high inc): $\downarrow$ choices \\
\hline Elkins-Brown et al., 2016 & go/no-go & yes & EMG & error: $\uparrow$ (corrugator supercilii) \\
\hline Elkins-Brown et al., 2017, Exp. 2 & flanker & yes & EMG & error: $\uparrow$ (corrugator supercilii) \\
\hline Fenske et al., 2005 & go/no-go & yes & rating of target & NoGo: $\downarrow$ rating (trust) \\
\hline Ferrey et al., 2012, Exp. 1 & go/no-go & yes & rating of target & NoGo: $\downarrow$ rating (attractivity) \\
\hline Ferrey et al., 2012, Exp. 2 & go/no-go & yes & rating of target & NoGo: $\downarrow$ rating (attractivity) \\
\hline Fiehler et al., 2004 & flanker & yes & heart rate & inc \& error: $\downarrow$ heartrate \\
\hline Frischen et al., 2012, Exp. 1 & go/no-go & yes & rating of target & NoGo: $\downarrow$ rating (trust) \\
\hline Frischen et al., 2012, Exp. 2 & go/no-go & yes & rating of target & NoGo: $\downarrow$ rating (attractivity) \\
\hline Frischen et al., 2012, Exp. 3 & go/no-go & yes & rating of target & NoGo: $\downarrow$ rating (liking) \\
\hline Frischen et al., 2012, Exp. 4 & go/no-go & yes & rating of target & NoGo: $\downarrow$ rating (liking) \\
\hline Fritz \& Dreisbach, 2013 & Stroop & no & AMP & inc: $\downarrow$ rating (neg) \\
\hline Fritz \& Dreisbach, 2015, Exp. 1 & Stroop & no & AMP & inc: $\downarrow$ Rating (neg) with short SOA \\
\hline Fritz \& Dreisbach, 2015, Exp. 2 & Stroop & no & AMP & inc: $\downarrow$ Rating (neg) with short SOA \\
\hline Fritz \& Dreisbach, 2015, Exp. 3 & Stroop & no & AMP & inc: $\downarrow$ Rating (neg) with short SOA \\
\hline Fröber et al., 2017 & Simon & yes & rating of trials & inc: $\downarrow$ Rating (neg) \\
\hline Gold et al., 2015, Exp. 1 & task switching & yes & task choice & context (high inc): $\downarrow$ choices \\
\hline Gold et al., 2015, Exp. 2 & task switching & yes & task choice & context (high inc): no effect \\
\hline Gold et al., 2015, Exp. 3 & task switching & yes & task choice & context (high inc): $\downarrow$ choices \\
\hline Goller et al., 2017, Exp. 1 & flanker & yes & AMP & inc: $\uparrow$ rating (neg), only subliminal \\
\hline Goller et al., 2017, Exp. 2 & flanker & yes & AMP & inc: $\uparrow$ rating (neg), only subliminal \\
\hline Goller et al., 2017, Exp. 3 & flanker & yes & AMP & inc: $\uparrow$ rating (neg), only subliminal \\
\hline Hajcak \& Foti, 2008 & flanker & yes & startle & error: $\uparrow$ startle \\
\hline Hajcak et al., 2003 & Stroop & yes & SCR, heartrate & error: $\uparrow$ SCR \& $\downarrow$ heartrate; inc: no effect \\
\hline Hajcak et al., 2004 & Stroop & yes & SCR, heartrate & error: $\uparrow$ SCR $\& \downarrow$ heartrate; inc: no effect \\
\hline Hatukai \& Algom, 2017, Exp. 7 & Stroop & yes & affective-mapping task & inc: $\downarrow$ RT (neg) \\
\hline Hochman et al., 2017, Exp. 1 & flanker & yes & force of key-release & error: $\uparrow$ force of keyrelease \\
\hline Hochman et al., 2017, Exp. 2 & flanker & yes & RT of key-release & error: $\downarrow$ RT keyrelease \\
\hline Ivanchei et al., 2018 & flanker & yes & affective priming & inc \& error: $\downarrow$ RT (neg) \\
\hline Kiss et al., 2008 & go/no-go & yes & rating of target & NoGo: $\downarrow$ rating (trust) \\
\hline Kobayashi et al., 2007, Exp. 1 & Stroop & yes & SCR & inc \& error: $\uparrow$ SCR \\
\hline Kobayashi et al., 2007, Exp. 2 & Stroop & yes & SCR & inc \& error: $\uparrow$ SCR \\
\hline
\end{tabular}


Table 1 (continued)

\begin{tabular}{|c|c|c|c|c|}
\hline Reference & Task & $\begin{array}{l}\text { Response to } \\
\text { Conflict }\end{array}$ & DV Affect & Finding \\
\hline Kool et al., 2010, Exp. 1 & task switching & yes & task choice & context (high inc): $\downarrow$ choices \\
\hline Kool et al., 2010, Exp. 3 & task switching & yes & task choice & context (high inc): $\downarrow$ choices \\
\hline Kool et al., 2010, Exp. 5 & task switching & yes & task choice & context (high inc): $\downarrow$ choices \\
\hline Kool et al., 2013 & task switching & yes & task choice & context (high inc): $\downarrow$ choices \\
\hline Kuipers et al., 2017 & flanker & yes & $\begin{array}{l}\text { heart beta-adrenergic ac- } \\
\text { tivity }\end{array}$ & inc: $\uparrow$ beta-adrenergic activity \\
\hline Ligeza \& Wyczesany, 2017 & flanker & yes & EEG for pictures & inc: $\uparrow$ late positive potential (neg) \\
\hline Lindström et al., 2013 & go/no-go & yes & EMG & error \& high inc: $\uparrow$ (corrugator supercilii) \\
\hline $\begin{array}{l}\text { Martiny-Huenger et al., 2014, Exp. } \\
\quad 1\end{array}$ & flanker & yes & $\begin{array}{l}\text { rating of target \& } \\
\quad \text { distractor }\end{array}$ & inc: $\uparrow$ rating (neg) \\
\hline $\begin{array}{l}\text { Martiny-Huenger et al., 2014, Exp. } \\
\quad 2\end{array}$ & flanker & yes & $\begin{array}{l}\text { rating of Target \& } \\
\text { Distractor }\end{array}$ & inc: $\uparrow$ rating (neg) \\
\hline McGuire \& Botvinick, 2010, Exp.1 & task switching & yes & task choice & context (high inc): $\downarrow$ choices \\
\hline McGuire \& Botvinick, 2010, Exp.2 & task switching & yes & task choice & context (high inc): $\downarrow$ choices \\
\hline Morsella et al., 2009, Exp. 1 & Stroop & yes & $\begin{array}{l}\text { post experimental } \\
\text { questions }\end{array}$ & inc: $\uparrow$ rating (avoidance) \\
\hline Morsella et al., 2009, Exp. 2 & Stroop & yes & $\begin{array}{l}\text { post experimental } \\
\text { questions }\end{array}$ & inc: $\uparrow$ rating (avoidance) \\
\hline Naccache et al., 2005, Exp. 9 & Stroop & yes & SCR & inc: $\uparrow \mathrm{SCR}$ \\
\hline Pan et al., 2016, Exp. 1 & Stroop & no & affective priming \& EEG & inc: $\downarrow$ RT (neg); $\uparrow$ N400 (neg) \\
\hline Regenberg et al., 2012, Exp. 1 & grasp-CE & yes & AMP & inc: $\uparrow$ rating (neg) \\
\hline Regenberg et al., 2012, Exp. 2 & grasp-CE & yes & rating of trials & inc: $\uparrow$ rating (neg) \\
\hline Renaud, \& Blondin, 1997 & Stroop & yes & SCR & inc: no SCR effect \\
\hline Riesel et al., 2013 & flanker & yes & startle & error: $\uparrow$ startle \\
\hline Sayalı \& Badre, 2019, Exp.1 & task switching & yes & task choice & context (high inc): $\downarrow$ choices \\
\hline Sayalı \& Badre, 2019, Exp.2 & task switching & yes & task choice & context (high inc): no effeect \\
\hline Schacht et al., 2010 & go/no-go \& Simon & yes & SCR, startle & NoGo: $\downarrow$ startle $\& \downarrow$ SCR; Simon: no effect \\
\hline Schacht et al., 2009, Exp. 1 & go/no-go & yes & EMG, SCR & NoGo: $\uparrow$ (corrugator supercilii) $\& \downarrow$ SCR \\
\hline Schacht et al., 2009, Exp. 2 & go/no-go & yes & EMG, SCR, startle & NoGo: $\uparrow$ (corrugator supercilii) $\& \downarrow$ startle \\
\hline Schacht et al., 2009, Exp. 4 & go/no-go & yes & EMG, SCR, startle & $\begin{array}{l}\text { NoGo: } \uparrow \text { (corrugator supercilii) } \& \downarrow \text { startle } \& \downarrow \\
\quad \text { SCR }\end{array}$ \\
\hline Schouppe et al., 2014 & flanker & yes & task choice & context (high inc): $\downarrow$ choices \\
\hline Schouppe et al., 2015, Exp. 1 & flanker & no & affective priming & inc: $\downarrow$ RT (neg) \\
\hline Schouppe et al., 2015, Exp. 2 & flanker \& Stroop & yes & affective priming & inc: $\uparrow \mathrm{RT}$ (neg) \\
\hline Schouppe et al., 2012 & Stroop & no & approach avoidance task & inc: $\downarrow$ RT (avoidance) \\
\hline Schupp et al., 1994, Exp.1 & go/no-go & yes & startle & NoGo: $\downarrow$ startle \\
\hline Schupp et al., 1994, Exp.2 & go/no-go & yes & startle & NoGo: $\downarrow$ startle \\
\hline Spruit et al., 2018 & $\begin{array}{l}\text { flanker \& task } \\
\text { switching }\end{array}$ & yes & $\begin{array}{l}\text { heart beta-adrenergic ac- } \\
\text { tivity }\end{array}$ & error: $\uparrow$ beta-adrenergic activity \\
\hline Spunt et al., 2012 & stop-signal & yes & rating of trials & inc: $\uparrow$ Rating (neg) \\
\hline Van der Veen et al., 2000 & go/no-go & yes & heart rate & inc: $\downarrow$ heartrate \\
\hline Vermeylen et al., 2019, Exp. 1 & task switching & yes & AMP & inc: $\uparrow \mathrm{RT}$ (neg) \\
\hline Vermeylen et al., 2019, Exp. 2 & task switching & yes & AMP & inc: $\uparrow$ RT (neg) \\
\hline Waid \& Orne, 1982 & Stroop & yes & SCR & inc: $\uparrow \mathrm{SCR}$ \\
\hline $\begin{array}{l}\text { van der Wel \& van Steenbergen, } \\
2018\end{array}$ & review & yes & pupil diameter & inc: $\uparrow$ pupil diameter \\
\hline
\end{tabular}

$\mathrm{RT}=$ reaction time; $\mathrm{SCR}=$ skin conductance response; inc = incongruent; neg = negative; grasp-CE = grasp-compatibility effect; EMG = electromyogram; $\mathrm{AMP}=$ affective misattribution procedure; $\mathrm{EEG}=$ electroencephalogram

\section{Conflict triggers affect-The conflict $\otimes$ affect link}

What are the downstream consequences of conflict? A direct prediction of the affective-signaling hypothesis is that conflict and errors elicit negative affect. Therefore, evidence is reviewed that manipulated conflict/errors experimentally and examined affective reactions (for an overview, see Table 1).
Conflict is aversive Studies that used explicit measures of affect asked participants to report their subjective feelings during conflict and nonconflict trials (Stroop: Morsella, Gray, Krieger, \& Bargh, 2009; Simon: Fröber, Stürmer, Frömer, \& Dreisbach, 2017; grasp compatibility: Regenberg, Häfner, \& Semin, 2012, Exp. 2; errors: Spunt, Lieberman, Cohen, \& Eisenberger, 2012). Implicit measures of affect using 
behavioral indices of affect provided converging evidence for an affective evaluation of conflict using different measures of affect. In the affective priming procedure (Fazio, Sanbonmatsu, Powell, \& Kardes, 1986), a prime stimulus (e.g., a Stroop color word) is presented before a clearly positive or negative target stimulus (e.g., a picture). Participants are instructed to categorize the valence of the target as quickly and accurately as possible. Several studies found faster responses for negative targets following an incongruent as compared to a congruent prime and faster response for positive targets following an congruent as compared to an incongruent prime (grasp compatibility effect: Brouillet, Ferrier, Grosselin, \& Brouillet, 2011; Stroop: Dreisbach \& Fischer, 2012; Pan et al., 2016, Exp. 1; flanker: Ivanchei et al., 2018; Schouppe et al., 2015, Exp. 1). The affective priming paradigm also provided evidence for negative affective responses following errors (go/no-go task: Aarts, De Houwer, \& Pourtois, 2012, 2013; De Saedeleer \& Pourtois, 2016). Further support for a priming of negative affect by conflict comes from an EEG study that observed an increased late positive potential for negative pictures following flanker conflict, suggesting enhanced processing of negative pictures after conflict (Ligeza \& Wyczesany, 2017; but see Steinhauser, Flaisch, Meinzer, \& Schupp, 2016).

Another task for an indirect measurement of affective reactions is the affect misattribution procedure (AMP; Payne, Cheng, Govorun, \& Stewart, 2005). In this task, participants are presented with a prime stimulus (e.g., a Stroop color word) that is followed by a neutral target stimulus (e.g., a Chinese character). Participants should evaluate the neutral target by pressing a positive or a negative response key. Studies showed that the evaluations of neutral targets were more negative following a conflict prime relative to a nonconflict prime stimulus (Stroop: Damen, Strick, Taris, \& Aarts, 2018; Fritz \& Dreisbach, 2013, 2015; grasp compatibility: Regenberg et al., 2012, Exp.1; flanker: Goller, Khalid, \& Ansorge, 2017; MartinyHuenger, Gollwitzer, \& Oettingen, 2014; task switching: Vermeylen, Braem, \& Notebaert, 2019; go/no-go task: Buttaccio \& Hahn, 2010; Doallo et al., 2012; Fenske, Raymond, Kessler, Westoby, \& Tipper, 2005; Ferrey, Frischen, \& Fenske, 2012; Frischen, Ferrey, Burt, Pistchik, \& Fenske, 2012; Kiss, Raymond, Westoby, Nobre, \& Eimer, 2008; errors: Chetverikov et al., 2017).

Physiological evidence for a negative evaluation of conflicts and errors comes from electromyographic recordings of the zygomaticus major (the "smiling muscle" involved in positive affect). One study observed increased activity for congruent relative to incongruent trials in a combined Simon/grasp compatibility task (Cannon, Hayes, \& Tipper, 2010). Furthermore, recordings of the corrugator supercilii (the "frowning' muscle" involved in negative affect) during a go/no-go task showed increased activity following conflict (Lindström, Mattsson-Mårn, Golkar, \& Olsson, 2013; Schacht, Nigbur, \& Sommer, 2009) and errors (Elkins-Brown, Saunders, He, \& Inzlicht, 2017, Exp. 2; Elkins-Brown, Saunders, \& Inzlicht, 2016; Lindström et al., 2013).

Further evidence for the negative evaluation of conflict comes from a study that used repetition suppression (a technique that is based on the observation that repeated activation of the same brain areas reduces activation of the neural system) and found that dACC responses to negative pictures were reduced following conflict as compared to nonconflicting trials, suggesting that conflict already triggered the same neural representation as the negative pictures (Braem et al., 2017).

Several studies also showed that conflict-related stimuli trigger behavioral avoidance (Dignath \& Eder, 2015; Hatukai \& Algom, 2017; Schouppe, De Houwer, Ridderinkhof, \& Notebaert, 2012). Similarly, errors (Hochman, Milman, \& Tal, 2017) and tasks associated with conflict and errors facilitate avoidance behavior (Botvinick, Huffstetler, \& McGuire, 2009; Botvinick \& Rosen, 2009; Desender, Buc Calderon, van Opstal, \& van den Bussche, 2017; Dignath, Kiesel, \& Eder, 2015; Dunn, Gasper, \& Risko, 2018; Gold, Kool, Botvinick, Hubzin, August, \& Waltz, 2015; Kool, McGuire, Rosen, \& Botvinick, 2010; Kool, McGuire, Wang, \& Botvinick, 2013; McGuire \& Botvinick, 2010; Schouppe, Ridderinkhof, Verguts, \& Notebaert, 2014; Sayalı \& Badre, 2019). In addition to studies showing that conflict triggers negative affect, we now review studies on the relationship between conflict/errors and arousal.

Conflict is arousing Evidence for an arousing effect of conflict comes from physiological studies. Skin conductance responses increase during conflict (Stroop: Kobayashi, Yoshino, Takahashi, \& Nomura, 2007; Naccache et al., 2005, Exp. 9; Renaud \& Blondin, 1997; Waid \& Orne, 1982; but see Schacht, Dimigen, \& Sommer, 2010; Schacht, Nigbur, \& Sommer, 2009, for the reverse pattern in the go/nogo task) and after errors (Hajcak, McDonald, \& Simons, 2003, 2004). Furthermore, many studies reported increased pupil diameter in incongruent as compared to congruent Stroop task trials (for a review, see van der Wel \& van Steenbergen, 2018). Studies also found a decelerated heart beat in incongruent trials (flanker: Fiehler, Ullsperger, Grigutsch, \& von Cramon, 2004; Kuipers et al., 2017; go/no-go: Hajcak et al., 2003; van der Veen, van der Molen, \& Jennings, 2000) and after errors (Fiehler et al., 2004; Hajcak et al., 2003). Conflict (Kuipers et al., 2017) and errors (Spruit, Wilderjans, \& van Steenbergen, 2018) also increase sympathetic beta-adrenergic activity of the heart. Some studies found that the protectivedefensive startle reflex is potentiated after errors (Hajcak \& Foti, 2008; Riesel, Weinberg, Moran, \& Hajcak, 2013). However, this finding is inconsistent with studies reporting a 
reduced startle reflex potentiation in conflict trials (go/no-go $\operatorname{task}^{3}$ : Schacht et al., 2010; Schacht et al., 2009; Schupp, Lutzenberger, Rau, \& Birbaumer, 1994).

\section{Conflict is registered as an affective signal-The affect $\otimes$ monitoring link}

According to the affective-signaling hypothesis, the affective reaction to conflict is registered by a monitoring system. This raises the possibility that affective states systematically alter the monitoring of conflicts and errors. In this section, we provide an overview of research that directly tested this assumption. First, correlational evidence is reviewed testing the prediction that monitoring of conflict-triggered negative affect should be increased for individuals who experience more and stronger negative affect. This line of argumentation is complemented by studies that have tested the prediction that experimental induction of negative affect should boost the monitored affective consequences of conflict and errors. Table 2 summarizes this literature.

\section{Correlational evidence for the affect $\otimes$ monitoring link The} most compelling evidence for a relationship between affect and monitoring comes from studies investigating interindividual differences in electrophysiological responses to errors and conflict. Numerous reviews and meta-analyses overlooking more than 50 studies reached the conclusion that chronic dispositions to negative affect are associated with enhanced processing of errors and conflict. Specifically, trait negative affect, avoidance dispositions, depression, general anxiety, symptoms of worry, and social distress in both clinical and nonclinical populations correlate positively with N2/N450 and ERN amplitudes (Cavanagh \& Shackman, 2015; Endrass \& Ullsperger, 2014; Koban \& Pourtois, 2014; Meyer, 2017; Moser, Moran, Schroder, Donnellan, \& Yeung, 2013; Weinberg, Dieterich, \& Riesel, 2015).

However, the conclusions drawn from these relationships varied considerably. Koban and Pourtois (2014) suggested that errors (but not conflict) activate brain areas involved in affective processing outside the dACC (e.g., the amygdala). Cavanagh and Shackman (2015) proposed that negative affect and conflict are integrated within the dACC to guide adjustments of cognitive control. Moser et al. (2013) hypothesized that the increased ERN in anxiety reflects the distracting effects of worry. Particularly the latter idea illustrates a general problem of these correlative studies. It is unclear whether it is affect that directly has an impact on monitoring or whether it is a third variable such as the susceptibility to rumination that mediates the effect of affect on monitoring

\footnotetext{
${ }^{3}$ It should be noted that the go/no-go task confounds no-conflict/conflict with action/no-action, which could provide an alternative explanation for the startle modulation here.
}

(Moser et al., 2013). This ambiguity limits the utility of correlative evidence for a strong evaluation of the affectivesignaling hypothesis. However, if a relationship between negative affect and enhanced monitoring of errors and conflicts would exist, one would expect analogous results for studies that manipulate affective states experimentally.

Experimental evidence for the affect $\nabla$ monitoring link The majority of experimental studies manipulated mood states using induction methods such as autobiographical scripts and imagery (Larson, Gray, Clayson, Jones, \& Kirwan, 2013; Nixon, Liddle, Nixon, \& Liotti, 2013; Paul, Walentowska, Bakic, Dondaine, \& Pourtois, 2017); emotional movies (Olvet \& Hajcak, 2011; Y. Wang, Yang, \& Wang, 2014); encouraging feedback (Clayson, Clawson, \& Larson, 2011; Wiswede, Münte, \& Rüsseler, 2009); facial feedback (Wiswede, Münte, Krämer, \& Rüsseler, 2009); social exclusion (Otten \& Jonas, 2014; Themanson, Ball, Khatcherian, \& Rosen, 2014); in vivo confrontation with spiders (Moser, Hajcak, \& Simons, 2005); affective touch (Saunders, Riesel, Klawohn, \& Inzlicht, 2018); or induction of helplessness (Pfabigan et al., 2013).

Of those studies that analyzed the ERN, only five of them found a valence effect in the expected direction, that is, a larger ERN for negative than for positive or neutral valence (Pfabigan et al., 2013; Wiswede, Münte, \& Rüsseler, 2009), a smaller ERN for positive than for neutral valence (Wiswede, Münte, Krämer, \& Rüsseler, 2009; see also Hobson, Saunders, Al-Khindi, \& Inzlicht, 2014), or a smaller ERN when negative affective states were successfully suppressed (Y. Wang, Yang, \& Wang, 2014), whereas two studies showed opposite effects (Saunders et al., 2018; Themanson et al., 2014). Related, Inzlicht and Al-Khindi (2012) used a misattribution procedure to assess the effect of affective states on error monitoring. More precisely, the authors speculated that participants should discount a negative affective response to errors in a condition in which they believed that they would experience negative affect that was unrelated to conflict. Although their study revealed evidence for a reduced ERN in this condition as compared to control, two recent follow-up studies failed to replicate the finding (Cano Rodilla, Beauducel, \& Leue, 2016; Elkins-Brown, Saunders, \& Inzlicht, 2018).

Five studies have investigated a modulation of N2/N450 responses, and only one of them found that tonic negative valence increased the N2 (Otten \& Jonas, 2014), whereas two studies found the opposite effect (Nixon et al., 2013; Yuan et al., 2011), and the others reported null effects (Clayson et al., 2011).

A few studies have induced phasic affect with presentations of affective stimuli prior to each trial. Wiswede, Münte, Goschke, and Rüsseler (2009) reported increased ERNs in a flanker task following negative affective pictures (but no effect on the N2). A study by Boksem, Ruys, and Aarts (2011) 
Table 2 Data from studies that have investigated affective modulation of the N2 and ERN (the affect $\square$ monitoring link)

\begin{tabular}{|c|c|c|c|c|c|}
\hline Reference & Task & $\begin{array}{l}\text { Affect } \\
\text { induction }\end{array}$ & Design & Manipulation & Finding \\
\hline Böckler et al., 2011 & Simon & phasic & experimental & accessory tone & $\Delta$ (inc-con) N2: arousal = no-arousal \\
\hline Boksem et al., 2011 & Simon & phasic & experimental & faces & ERN (disgusted) > ERN (happy, sad) \\
\hline $\begin{array}{l}\text { Elkins-Brown et al., } \\
2018\end{array}$ & go/no-go & phasic & experimental & missattribution & ERN $($ missattribution $)=$ ERN $($ control $)$ \\
\hline $\begin{array}{l}\text { Inzlicht \& Al-Khindi, } \\
\quad 2012\end{array}$ & go/no-go & phasic & experimental & missattribution & ERN (missattribution) < ERN (control) \\
\hline Kanske \& Kotz, 2010 & flanker & phasic & experimental & words & $\Delta$ (inc-con) $\mathrm{N} 2:($ neg) $>$ (neu) \\
\hline Kanske \& Kotz, 2011a & Simon & phasic & experimental & words & $\Delta$ (inc-con) $\mathrm{N} 2:($ pos $)>($ neu $)$ \\
\hline Kanske \& Kotz, 2011b & Simon & phasic & experimental & words & $\Delta$ (inc-con) $\mathrm{N} 2:($ neg) $>$ (neu) \\
\hline Kanske \& Kotz, 2011c & flanker & phasic & experimental & words & $\Delta$ (inc-con) $\mathrm{N} 2:($ neg $)>($ neu $)$ \\
\hline Larson et al., 2006 & flanker & phasic & experimental & pictures & ERN (pos) > ERN (neg, neu) \\
\hline Li et al., 2014 & flanker & phasic & experimental & words & no N2 effect \\
\hline Cano Rodilla et al., 2016 & go/no-go & phasic & experimental & missattribution & ERN $($ missattribution $)=$ ERN $($ control $)$ \\
\hline Roh et al., 2016 & flanker & phasic & experimental & faces & $\begin{array}{l}\text { ERN (fearful) > ERN (neutral) in OCD patient, not in } \\
\text { controls }\end{array}$ \\
\hline Senderecka et al., 2018 & stop signal task & phasic & experimental & words & no ERN effect \\
\hline Senderecka, 2016 & stop signal task & phasic & experimental & pictures & no ERN effect; N2 (neg) > N2 (neu) \\
\hline Senderecka, 2018 & stop signal task & phasic & experimental & sounds & no ERN effect \\
\hline Wiswede et al., 2009 & flanker & phasic & experimental & pictures & ERN (neg) > ERN (pos, neu); no N2 effect \\
\hline Xue et al., 2013 & Simon & phasic & experimental & faces & $\Delta$ (inc-con) N450: (pos) $>$ (neu) \\
\hline Zhang et al., 2018 & flanker & phasic & experimental & words & $\Delta$ (inc-con) $\mathrm{N} 2:($ neg $)>($ neu $)$ \\
\hline Clayson et al., 2011 & flanker & tonic & experimental & blockwise feedback & no ERN/N2 effects \\
\hline Hobson et al., 2014 & go/no-go & tonic & experimental & emotion regulation & $\begin{array}{l}\mathrm{ERN} \text { (down) < ERN (up, control), mediated by emotion } \\
\text { ratings }\end{array}$ \\
\hline Larson et al., 2013 & flanker & tonic & experimental & music-imagination & no ERN effect (only CRN varied with arousal) \\
\hline Moser et al., 2005 & flanker & tonic & experimental & $\begin{array}{l}\text { spider vs. ball in } \\
\text { hand }\end{array}$ & no ERN effect \\
\hline Nixon et al., 2013 & Stroop & tonic & experimental & $\begin{array}{l}\text { autobiographical } \\
\text { scripts }\end{array}$ & N450 (sad) < N450 (control), no ERN reported \\
\hline Olvet \& Hajcak, 2011 & flanker & tonic & experimental & movies & no ERN effect; change in mood predicted ERN \\
\hline Otten \& Jonas, 2014 & go/no-go & tonic & experimental & social exclusion & N2 (exclusion) > N2 (inclusion), no ERN reported \\
\hline Paul et al., 2017 & go/no-go & tonic & experimental & imagery & no ERN effect, N2 not reported \\
\hline Pfabigan et al., 2013 & flanker & tonic & experimental & $\begin{array}{l}\text { learned } \\
\text { helplessness }\end{array}$ & $\begin{array}{l}\text { ERN (helpless) > ERN (non-helpless), correlation } \\
\text { ERN-helplessness }\end{array}$ \\
\hline Saunders et al., 2018 & go/no-go & tonic & experimental & affective touch & ERN (pos) > ERN (neu) \\
\hline Themanson et al., 2014 & flanker & tonic & experimental & social exclusion & ERN (exlusion) < ERN (inclusion) (pre-post) \\
\hline Wang et al., 2014 & Stroop & tonic & experimental & emotion regulation & $\mathrm{EN}($ supp$)<\mathrm{ERN}($ reapp, contr), no N450 effect \\
\hline Wiswede et al., 2009 & flanker & tonic & experimental & $\begin{array}{r}\text { block-wise } \\
\text { feedback }\end{array}$ & ERN (neg) $>$ ERN (pos) \\
\hline Wiswede et al., 2009 & flanker & tonic & experimental & facial feedback & ERN (pos) < ERN (neu) \\
\hline Yuan et al., 2011 & Stroop & tonic & experimental & sounds & N450 (pos) > N450 (neu, neg) \\
\hline $\begin{array}{l}\text { Cavanagh \& Shackman, } \\
2015\end{array}$ & meta-analysis & trait & correlational & / & $\uparrow$ anxiety disorders \& $\uparrow$ ERN \& N2 \\
\hline $\begin{array}{l}\text { Endrass \& Ullsperger, } \\
\quad 2014\end{array}$ & review & trait & correlational & l & $\uparrow \mathrm{OCD} \& \uparrow \mathrm{ERN}$ \\
\hline Koban \& Pourtois, 2014 & review & trait & correlational & l & $\uparrow$ negative affect $\& \uparrow \mathrm{ERN}$ \\
\hline Meyer, 2017 & review & trait & correlational & / & $\uparrow$ anxiety disorders in children (6-18 years) $\& \uparrow \mathrm{ERN}$ \\
\hline Moser et al., 2013 & meta-analysis & trait & correlational & / & $\uparrow$ anxiety disorders $\& \uparrow$ ERN \\
\hline Weinberg et al., 2015 & review & trait & correlational & / & $\uparrow$ negative affect $\& \uparrow$ ERN \\
\hline
\end{tabular}

inc = incongruent ; con = congruent neg = negative; pos = positive; neu = neutral; $\mathrm{OCD}=$ obsessive compulsive disorder 
found increased ERNs after presentation of disgusting faces relative to neutral faces. However, sad faces did not produce an effect relative to neutral faces. Furthermore, Larson, Perlstein, Stigge-Kaufman, Kelly, and Dotson (2006) obtained an increased ERN following positive affective pictures, in contradiction to the prediction that negative affect should enhance the ERN response. Roh, Chang, and Kim (2016) found no such effect in healthy participants, but an increased ERN to fearful faces in patients with obsessive compulsive disorder. Results with measurements of the N2/N450 response were more univocal. Here several studies reported an increased $\mathrm{N} 2 / \mathrm{N} 450$ response after presentations of negative and positive (as compared to neutral) words prior to flanker or Simon task trials (Kanske \& Kotz, 2010, 2011 a, 2011b, 2011c; Xue et al., 2013; Zhang, Teo, \& Wu, 2018; stop-signal task: Senderecka, 2016; but see Li et al., 2014, for a failure to replicate). In sum, evidence for tonic and phasic affective influences on monitoring is rather ambiguous.

\section{Conflict-triggered affect drives control adaptation-The affect $\otimes$ control link}

According to the affective-signaling hypothesis, conflicttriggered negative affect serves as a learning signal for control adaptation. As we described above in more detail, most studies have indexed adaption of control with the sequential congruency effect. In this part, evidence is reviewed from investigations of the relationship between negative affect and the size of the sequential congruency effect (for an overview, see Table 3). We first describe studies that tested a correlation between affective traits and the sequential congruency effect. If conflict-triggered negative affect drives conflict adaptation, the sequential congruency effect should be increased for persons that experience more negative affect. Then, we review studies that experimentally manipulated tonic or phasic affects and tested the prediction that induction of negative affect should increase the negative learning signal for control adaptation and result in a larger sequential congruency effect.

Correlational evidence for the affect $\otimes$ control link Some studies have suggested that sequential congruency effects are increased for participants with high anxiety (Booth \& Peker, 2017; Larson, Clawson, Clayson, \& Baldwin, 2013). However, this link between the sequential congruency effect and anxiety has not been replicated by others (A. L. Gold, Jarcho, Rosen, Pine, \& Ernst, 2015; Krug \& Carter, 2010; Osinsky, Alexander, Gebhardt, \& Hennig, 2010; Osinsky, Gebhardt, Alexander, \& Hennig, 2012). The results for mood disorders are also mixed. Two studies showed that participants with depression produce stronger sequential congruency effects (Larson, Clawson, et al., 2013; van Steenbergen, Booij, Band, Hommel, \& van der Does, 2012), whereas others found no difference (Clawson, Clayson, \& Larson, 2013; West,
Choi, \& Travers, 2010), or the reversed pattern (Holmes \& Pizzagalli, 2007).

Another study showed that sequential congruency effects were stronger for participants who score high in alertness (as indexed by the attentional network test; Liu, Yang, Chen, Huang, \& Chen, 2013). De Galan and colleagues showed that participants who scored high on the cognitive dimension of alexithymia, which is associated with difficulties to identify and express or describe own emotions, show reduced sequential congruency effect (de Galan, Sellaro, Colzato, \& Hommel, 2014; see also Maier, Scarpazza, Starita, Filogamo, \& Làdavas, 2016, for related evidence regarding the ERN).

\section{Experimental evidence for the affect $\otimes$ control link Many} studies have reported an affective modulation of control by tonic affect. These studies induced mood states with movie clips (Schuch \& Koch, 2015), music and imagination (van Steenbergen, Band, \& Hommel, 2010), cartoons (van Steenbergen, Band, Hommel, Rombouts, \& Nieuwenhuis, 2015), approach/avoidance gestures (Hengstler, Holland, van Steenbergen, \& van Knippenberg, 2014), mock feedback on either intelligence tests (Schuch \& Pütz, 2018; Schuch, Zweerings, Hirsch, \& Koch, 2017) or task performance (Yang \& Pourtois, 2018), or particular screen colors (X. Wang, Zhao, Xue, \& Chen, 2016). The studies consistently demonstrated that negative mood states increase sequential congruency effects, whereas positive mood states decrease sequential congruency effects.

For the induction of phasic affect, studies have intermixed presentations of affective stimuli (pictures, words, monetary rewards, etc.) at the time of presentation of the target or between trials. Van Steenbergen and colleagues observed a reduced sequential congruency effect following a (performance non-contingent) reward signal relative to a loss signal (van Steenbergen et al., 2009; see also van Steenbergen et al., 2012). They concluded that the reward signal was opposed to the negative conflict signal and therefore impaired control adaption. However, other experiments have failed to reproduce this effect (Stürmer, Nigbur, Schacht, \& Sommer, 2011, Exp. 1; Yamaguchi \& Nishimura, 2019, Exps. 2 and 3 ). Another study included high-arousing unpleasant and pleasant stimuli and found no difference in the magnitude of the sequential congruency effects for unpleasant and pleasant stimuli; however, the sequential congruency effect was increased by high arousal relative to a baseline condition with neutral stimuli (Zeng et al., 2017). This research suggests that arousal is more influential than affective valence for sequential congruency effect. However, a study that varied the arousal level systematically within each valence category observed no effect of valence and arousal on the size of sequential congruency effects in a Simon task (Dignath, Janczyk, \& Eder, 2017). Finally, increasing arousal more directly via vagus nerve stimulation (relative to a sham stimulation) 
Table 3 Data from studies that have investigated affective modulation of the sequential congruency effect (sequential congruency effect; the affect control link)

\begin{tabular}{|c|c|c|c|c|c|c|}
\hline Reference & Task & $\begin{array}{l}\text { Affect } \\
\text { Indcution }\end{array}$ & Design & Manipulation/ Trait & $\begin{array}{l}\text { FB } \\
\text { Control }\end{array}$ & Finding \\
\hline Becker et al., 2019, Exp. 1 & prime-target & phasic & experimental & gains/losses & post-hoc & SCE (neg $\mid$ pos) < SCE (neu) \\
\hline Becker et al., 2019, Exp. 2 & prime-target & phasic & experimental & gains/losses & post-hoc & SCE (neg $\mid$ pos) < SCE (neu) \\
\hline Becker et al., 2019, Exp. 3 & prime-target & phasic & experimental & gains/losses & a priori & SCE (neg $\mid$ pos) < SCE (neu) \\
\hline Böckler et al., 2011 & Simon & phasic & experimental & accessory tone & no & SCE $($ arousal $)=$ SCE $($ no-arousal $)$ \\
\hline Dignath et al., 2017, Exp. 1 & Simon & phasic & experimental & pictures & no & $\begin{array}{l}\text { SCE }(\text { neg, high })=\operatorname{SCE}(\text { neg, low })=\text { SCE } \\
\quad(\text { pos }, \text { high })=\operatorname{SCE}(\text { pos, low })\end{array}$ \\
\hline Dignath et al., 2017, Exp. 2 & Simon & phasic & experimental & pictures & no & $\begin{array}{l}\text { SCE }(\text { neg, high })=\text { SCE }(\text { neg, low })=\text { SCE } \\
\quad(\text { pos }, \text { high })=\text { SCE }(\text { pos, low })\end{array}$ \\
\hline Fischer et al., 2018 & flanker & phasic & experimental & $\begin{array}{l}\text { vagus nerve } \\
\text { stimulation }\end{array}$ & post-hoc & SCE (arousal) > SCE (sham) \\
\hline Fritz et al., 2015, Exp. 2 & Stroop & phasic & experimental & fluency & post-hoc & SCE $($ neg $)<$ SCE (pos) \\
\hline Fritz et al., 2015 Exp. 1 & flanker & phasic & experimental & fluency & post-hoc & errors: SCE (neg) < SCE (pos) \\
\hline Padmala et al., 2011 & Stroop & phasic & experimental & pictures & a priori & SCE (neg) < SCE (neu) \\
\hline Soutschek et al., 2013, Exp. 1 & Simon & phasic & experimental & accessory tone & post-hoc & SCE $($ arousal $)=$ SCE $($ no-arousal $)$ \\
\hline Soutschek et al., 2013, Exp. 2 & Stroop & phasic & experimental & accessory tone & post-hoc & SCE (arousal) < SCE (no-arousal) \\
\hline Stürmer et al., 2011 & Simon & phasic & experimental & gains/losses & no & $\operatorname{SCE}($ neg $)=\operatorname{SCE}($ pos $)=\operatorname{SCE}($ neu $)$ \\
\hline van Steenbergen et al., 2009 & flanker & phasic & experimental & gains/losses & no & $\operatorname{SCE}($ neg) $>$ SCE (pos) \\
\hline van Steenbergen et al., 2012 & flanker & phasic & experimental & gains/losses & no & SCE (neg) > SCE (pos) \\
\hline $\begin{array}{l}\text { Yamaguchi \& Nishimura, } \\
\text { 2019, Exp. } 2\end{array}$ & flanker & phasic & experimental & gains/losses & no & $\operatorname{SCE}($ neg $)=\operatorname{SCE}($ pos $)=\operatorname{SCE}($ neu $)$ \\
\hline $\begin{array}{l}\text { Yamaguchi \& Nishimura, } \\
\text { 2019, Exp. } 3\end{array}$ & flanker & phasic & experimental & gains/losses & no & $\operatorname{SCE}($ neg $)=\operatorname{SCE}($ pos $)=\operatorname{SCE}($ neu $)$ \\
\hline Zeng et al. 2017, Exp. 1 & flanker & phasic & experimental & words & no & SCE (neg $\mid$ pos) $>$ SCE (neu) \\
\hline Zeng et al. 2017, Exp. 2 & flanker & phasic & experimental & words & a priori & SCE (neg $\mid$ pos) $>$ SCE (neu) \\
\hline Hengstler et al., 2014, Exp. 1 & flanker & tonic & experimental & $\begin{array}{l}\text { approach/avoid. } \\
\text { blockwise }\end{array}$ & no & SCE (neg) $>$ SCE (pos) \\
\hline Hengstler et al., 2014, Exp. 2 & flanker & tonic & experimental & $\begin{array}{l}\text { approach/avoid. } \\
\text { blockwise }\end{array}$ & no & SCE (neg) > SCE (pos) \\
\hline Hengstler et al., 2014, Exp. 3 & flanker & tonic & experimental & $\begin{array}{l}\text { approach/avoid. } \\
\text { blockwise }\end{array}$ & a priori & SCE (neg) > SCE (pos) \\
\hline Schuch \& Koch, 2015, Exp. 1 & flanker & tonic & experimental & movies & post-hoc & errors: SCE (neg) > SCE (pos) \\
\hline Schuch \& Koch, 2015, Exp. 2 & Stroop & tonic & experimental & movies & post-hoc & $\operatorname{SCE}($ neg $)>\operatorname{SCE}($ pos $)$ \\
\hline Schuch \& Pütz, 2018 & task switch. & tonic & experimental & success/failure & post-hoc & task repetitions: SCE (neg) > SCE (pos) \\
\hline Schuch et al., 2017, Exp. 1 & flanker & tonic & experimental & success/failure & post-hoc & SCE (neg) $>$ SCE (pos) \\
\hline Schuch et al., 2017, Exp. 2 & Stroop & tonic & experimental & success/failure & post-hoc & errors: SCE (neg) > SCE (pos) \\
\hline van Steenbergen et al., 2010 & flanker & tonic & experimental & music/imagination & no & SCE (neg) $>$ SCE (pos) \\
\hline $\begin{array}{l}\text { van Steenbergen et al., 2015, } \\
\text { Exp. } 1\end{array}$ & flanker & tonic & experimental & $\begin{array}{l}\text { cartoons before block } \\
\text { of trials }\end{array}$ & no & $\mathrm{SCE}($ pos) $<\mathrm{SCE}$ (neutral) \\
\hline $\begin{array}{l}\text { van Steenbergen et al., 2015, } \\
\text { pilot }\end{array}$ & flanker & tonic & experimental & $\begin{array}{l}\text { cartoons before block } \\
\text { of trials }\end{array}$ & no & $\mathrm{SCE}($ pos) $<\mathrm{SCE}$ (neutral) \\
\hline Wang et al., 2016, Exp. 1 & flanker & tonic & experimental & background colour & a priori & $\begin{array}{l}\mathrm{SCE} \text { (low arousal) }<\mathrm{SCE} \text { (medium \& high } \\
\text { arousal) }\end{array}$ \\
\hline Wang et al., 2016, Exp. 2 & flanker & tonic & experimental & background colour & a priori & $\begin{array}{l}\mathrm{SCE} \text { (low arousal) }<\mathrm{SCE} \text { (medium \& high } \\
\text { arousal) }\end{array}$ \\
\hline Yang \& Pourtois, 2018, Exp. 1 & flanker & tonic & experimental & $\begin{array}{l}\text { blocks with/ without } \\
\text { contingent losses }\end{array}$ & no & SCE (neg) > SCE (neu) \\
\hline Yang \& Pourtois, 2018, Exp. 2 & flanker & tonic & experimental & $\begin{array}{l}\text { blocks with/ without } \\
\text { contingent losses }\end{array}$ & apriori & SCE (neg) > SCE (neu) \\
\hline Booth \& Peker, 2017 & Stroop & / & correlational & STAI & no & $\uparrow$ STAI \& $\uparrow$ SCE \\
\hline Clawson et al., 2013 & flanker & / & correlational & BDI & no & no: BDI \& SCE \\
\hline de Galan et al., 2014 & Simon & / & correlational & alexithymia & no & $\uparrow$ alexithymia (cogn. dimension) $\& \downarrow \mathrm{SCE}$ \\
\hline Fröber et al., 2017 & Simon & l & correlational & rating previous trial & no & negative rated trials \& SCE (errors) $\downarrow$ \\
\hline
\end{tabular}


Table 3 (continued)

\begin{tabular}{lllllll}
\hline Reference & Task & $\begin{array}{l}\text { Affect } \\
\text { Indcution }\end{array}$ & Design & Manipulation/ Trait & $\begin{array}{l}\text { FB } \\
\text { Control }\end{array}$ & Finding \\
\hline Gold et al., 2015 & Stroop & $/$ & correlational & STAI & no & no: STAI \& SCE \\
Holmes \& Pizzagalli, 2007 & Stroop & $/$ & correlational & BDI & no & $\downarrow$ BDI (negative feedback) \& SCE \\
Krug \& Carter, 2010 & Stroop & $/$ & correlational & STAI & no & SCE does not correlate with STAI \\
Larson et al., 2013 & flanker & $/$ & correlational & STAI \& BDI & no & $\uparrow$ STAI \& SCE $\uparrow$ BDI \& $\uparrow$ SCE \\
Liu et al., 2013, Exp. 1 & flanker & $/$ & correlational & ANT & a priori & $\uparrow$ alertness \& $\uparrow$ SCE \\
Liu et al., 2013, Exp. 2 & flanker & $/$ & correlational & ANT & a priori $\uparrow$ alertness \& $\uparrow$ SCE \\
Osinsky et al., 2010 & Stroop & $/$ & correlational & STAI & no & no: STAI \& SCE \\
Osinsky et al., 2012 & Stroop & $/$ & correlational & STAI & no & no: STAI \& SCE \\
van Steenbergen et al., 2012 & Simon & $/$ & correlational & MADRS & No & $\uparrow$ MADRS \& SCE \\
West et al., 2010 & Stroop & $/$ & correlational & BDI & no & no: BDI \& SCE \\
Zhao et al., 2018, Exp. 1 & flanker & $/$ & correlational & motivation & No & $\uparrow$ achievement motivation \& $\uparrow$ SCE \\
Zhao et al., 2018, Exp. 2 & flanker & $/$ & correlational & motivation & a priori & $\uparrow$ achievement motivation \& $\uparrow$ SCE \\
\hline
\end{tabular}

neg = negative; pos = positive; neu = neutral; avoid. = avoidance; SCE = sequential congruency effect STAI = State-Trait Anxiety Inventory; BDI = Beck Depression Index; ANT = attentional network test; MADRS = Montgomery-Åsberg Depression Rating Scale

resulted in larger sequential congruency effect than under sham treatment (Fischer, Ventura-Bort, Hamm, \& Weymar, 2018).

In contrast to the research reviewed above, another line of research suggests that high arousal/negative affect decreases the size of the sequential congruency effect. Padmala, Bauer, and Pessoa (2011) reported that presentations of negative pictures between trials eliminated the sequential congruency effect (relative to presentations of neutral pictures). The authors suggested that negative stimuli high in arousal draw attention away and occupy resources needed for control adaptation processes. This explanation is in line with other research showing that arousing accessory tones presented between trials reduced the sequential congruency effect in a Stroop task relative to a neutral baseline (Soutschek, Müller, \& Schubert, 2013, Exp. 2). However, it should be noted that this effect was not replicated in the Simon task (Böckler, Alpay, \& Stürmer, 2011; Soutschek et al., 2013, Exp. 1). Another study observed a reduced sequential congruency effect (relative to a neutral baseline) when cues associated with a reward or loss were presented simultaneously with the target (Becker, Jostmann, \& Holland, 2019). Negative arousal, induced by a processing fluency manipulation of target stimuli in a flanker or Stroop task, also diminished the sequential congruency effect relative to a condition with low arousing, positive affect (Fritz, Fischer, \& Dreisbach, 2015). A different research approach has been taken by a recent study by Fröber et al. (2017) who showed that the congruency effect is reduced following trials that were evaluated negatively by the participants. In this study, however, the experimenter had no control over the participants' affective ratings that were more negative for incongruent trials on average.

\section{Summary of the literature review}

The results from a large number of studies across different tasks and with a variety of affect measures support the conflict - affect link and show that conflict and errors trigger negative affect. Regarding the affect monitoring link, correlational evidence is in line with the idea that the affective consequences of conflict/ errors are monitored, although such an approach is clearly limited. However, experimental evidence is rather mixed. More specifically, it remains unclear how the induction of tonic and phasic affect influences the N2 and the ERN. Studies that addressed the affect $>$ control link provided some evidence for a link between negativity and increased sequential congruency effect. Experimental studies showed the most direct evidence that negative tonic affect increases the sequential congruency effect, which supports the idea that control adaptation is dependent on negative affect. However, this conjecture is not supported by the ambiguous results of those studies that induced phasic affect. Together, the literature review showed that while some key predictions of the affective-signaling hypothesis have been confirmed, others still require more empirical testing.

\section{Affective signaling-Challenges and future directions}

The previous parts of this review article have summarized research on the affective-signaling hypothesis. Together, we have shown that not all predictions of the affective-signaling hypothesis are supported by the available evidence. Do these inconsistencies falsify the affective-signaling hypothesis? Not 
necessarily, and this is due to the epistemological status of the affective-signaling hypothesis that refers more to a theoretical framework (that is consistent with a body of data) than to a testable theory (that can be falsified by a single experiment). In the context of discovery, this underspecification has a heuristic value and can stimulate new research, which is evidenced by the number of studies reviewed here. However, frameworks that specify global principles can also inspire more specific local theories that allow for a rigorous test and falsification. The next part of this article identifies several starting points for such local theories by discussing challenges and strategies for future research on the affective-signaling hypothesis.

\section{Specifying the role of resolved conflict and affect}

An important question is whether the conflict signal is best characterized by a negative affective state or by a transition from a negative to a positive affective state. Schouppe et al. (2015) showed that responding to an incongruent (flanker or Stroop) trial facilitated classifications of positive words relative to negative words (for a replication, see Ivanchei et al., 2018). According to this research, conflict resolution triggers positive affect. In support of this idea, Schouppe and colleagues suggested that results of a previous study by Fritz and Dreisbach (2015) could also be explained by positive affect following conflict resolution (Schouppe et al., 2015, p. 259). In this study, prolonged (passive) viewing of incongruent Stroop stimuli causes more positive evaluation in the AMP, possibly because participants resolved the conflict during the waiting period (for an analogous finding with the affective priming paradigm, see Pan et al., 2016, Exp. 2). Further correlational evidence comes from a study that found an increased sequential congruency effect for participants high in achievement motivation - a motive that affects motivational engagement in and positive experience of challenging tasks. This research suggests that resolution of conflict was particularly rewarding for participants high in achievement motive, which affected the size of conflict adaptation (Zhao, Jia, \& Maes, 2018).

However, it remains unclear how these results relate to studies that have observed negative affect after conflict in tasks in which participants actively responded to conflict (see the Response to Conflict column in Table 1). In a direct test between groups of participants who were actively responding a Stroop task and participants who were passively observing color words, Damen and colleagues observed no difference of affective evaluations between groups (Damen et al., 2018). More specifically, both active and passive groups showed more negative evaluations in the AMP following conflict. Accordingly, these findings do not support the hypothesis that actively resolved conflict is evaluated as positive.
Therefore, future research should systematically manipulate the response mode (active vs. passive) in responseinterference tasks to investigate conditions under which active responses to conflict changes the affective evaluation of conflict. Furthermore, more compelling evidence is needed for the hypothesis that conflict detection and resolution can be described by a transition of conflict-triggered affect from (initially) negative to more positive affect (following successful responding). Here, continuous physiological measures of affect like electromyography could provide a window into the on-line dynamics of conflict and response-triggered affect (cf. Dimberg, Thunberg, \& Elmehed, 2000).

\section{Tweaking manipulations of phasic affect}

As we discussed in detail before, results of phasic affect manipulations on the sequential congruency effect were ambiguous. These manipulations are based on the logic that phasic affect triggered by task-irrelevant stimuli should modulate the strength of the affective signal evoked by conflict (cf. van Steenbergen et al., 2009). However, this situation creates an affective credit assignment problem: How can the cognitive system know whether a given signal was triggered by conflict or whether it was triggered by an irrelevant event (Schuch, Dignath, Steinhauser, \& Janczyk, 2019)? Possibly, confusion of task-relevant (conflict-triggered) and-irrelevant (stimulustriggered) affect can account for the heterogeneity of results in this research area. Conflict-triggered compared to stimulustriggered affect might also be associated with different appraisal patterns - and hence cause different emotions (cf. Scherer \& Moors, 2019): Whereas the former state is attributed to one's own action, the latter state is explained with external events. If this conjecture is correct, factors that facilitate or impair the assignment of an affective state to its source should moderate how affective stimuli influence the sequential congruency effect. For example, temporal separation between two events should modulate the likelihood that affective information of these sources becomes integrated. Indeed, if affective stimuli and task-related stimuli were presented simultaneously, studies observed increased sequential congruency effects with affective stimuli (Zeng et al., 2017). In contrast, if affective stimuli and task-related stimuli were presented separately, studies observed no influence of affective stimuli on the sequential congruency effect (Dignath et al., 2017). Hence, more research is warranted that directly addresses how the timing of affective stimuli impacts the sequential congruency effect.

However, even if the affect resulting from conflict and taskirrelevant stimuli is combined, the outcome of this combination remains unclear. Whereas some studies have assumed that positive affective stimuli decrease the negativity of conflict (cf. van Steenbergen et al., 2009), research on "hedonic contrast" suggests that positive stimuli can also act as a background against which the registration of negative conflict is 
facilitated (Eder \& Dignath, 2014; Larsen \& Norris, 2009a, b). Indeed, studies showed that conflict in a context-specific learning paradigm was enhanced when presented together with positive as compared to negative stimuli (Dreisbach, Fröber, Berger, \& Fischer, 2019; Dreisbach, Reindl, \& Fischer, 2016; but see Zhang, Kiesel, \& Dignath, 2019, for a null effect). Clearly, more research is needed to get a better understanding of when and how task-irrelevant affect merges with task-relevant conflict-triggered affect.

Throughout this review, we adopted a dimensional view of affect (Barrett \& Russell, 1999) and conceptualized affect as a mixture of valence and arousal. However, theoretically it might be important to differentiate between both dimensions. For instance, Verguts and Notebaert suggested a model that accounts for control adaptation with states of high arousal. According to this theory, high arousal states promote feature binding between task-relevant stimuli and responses (Abrahamse, Braem, Notebaert, \& Verguts, 2016; Verguts \& Notebaert, 2009). The majority of studies examined a contribution of arousal by comparison of high-arousing negative and positive stimuli against low arousing neutral stimuli (see Tables 2 and 3 for an overview). However, it has been also suggested that valence and arousal can influence affective reactions in an interactive fashion (Eder \& Rothermund, 2010; Robinson, Storbeck, Meier, \& Kirkeby, 2004), and only few studies manipulated the valence and arousal of stimuli orthogonally (Dignath et al., 2017; van Steenbergen et al., 2010). More generally, the effect of affective stimuli on attention is caused by the interaction between properties of stimuli and the individuals' appraisal patterns (e.g., Brosch, Sander, Pourtois, \& Scherer, 2008; Wentura, Müller, \& Rothermund, 2014; Vogt, Lozo, Koster, \& De Houwer, 2011).

\section{Testing the causal role of affect for cognitive control}

Central to the affective-signaling hypothesis is the idea that conflict-triggered affect is causal for control adaptation. However, available evidence does not rule out the possibility that conflict-triggered affect is an epiphenomenon or that the influence of affect on cognitive control is more indirect. For instance, Fröber et al. (2017) examined a causal role of affect for conflict adaptation and observed increased sequential congruency effect in trials that were rated as unpleasant relative to trials that were rated as rather pleasant. However, subjective ratings of trials in conflict tasks are influenced by the magnitude of experienced conflict (cf. Abrahamse \& Braem, 2015; Foerster, Pfister, Reuss, \& Kunde, 2017). Accordingly, it is possible that those trials with a high level of conflict also triggered more control adaption in addition to, and independently of, ratings of unpleasantness. Future research could follow up on this task design, for instance by measuring EMG as an unobtrusive trial-to-trial assessment of affect in combination with mediation analysis. More specifically, one could hypothesize that the relationship between the congruency effect in trial $N-1$ and the reduction of the congruency effect in trial $N$ (i.e., the magnitude of sequential congruency effect) is mediated by the strength of EMG activity of the corrugator supercilii muscle (indicating negative affect). Relatedly, such online assessment of affective responses to conflict allows for a unobstrusive manipulation check of conflict-induced affect that does not interfere with conflict adaptation (in contrast to explicit ratings).

An alternative research strategy would be to directly change affect or arousal and assess the influence of this manipulation on control adaptation. Previous research already showed that increasing arousal via the locus coeruleusnoradrenaline system by means of vagus nerve stimulation increased control adaptation (Fischer, Ventura-Bort, Hamm, \& Weymar, 2018). Here future research could use psychopharmacological interventions to show that reduced affect is accompanied by a reduction in monitoring and control adaptation (see Randles, Kam, Heine, Inzlicht, \& Handy, 2016). Finally, research on error monitoring showed that a downregulation of negative emotions reduced the ERN (Hobson et al., 2014; Moser, Most, \& Simons, 2010). Future research may, therefore, use explicit emotion regulation strategies to modulate control adaptation. More specifically, one would expect a down-regulation of negative affective states to decrease the size of the sequential congruency effect.

\section{Disentangling the role of binding and control adaptation}

The interpretation of the affect control link is complicated by the fact that the sequential congruency effect in many reviewed studies can be alternatively explained with feature binding (Hommel, Proctor, \& Vu, 2004; Mayr, Awh, \& Laurey, 2003). According to a feature binding account, the sequential congruency effect reflects the costs/benefits to retrieve stimulus and response links from episodic memory. For instance, in a flanker task with two responses and two stimuli, target and distractor are repeated in two consecutive trials in half of the congruent trials (complete repetition), whereas they change across two consecutive trials in half of the incongruent trials (complete alternation). In the remaining trials with transitions from incongruent to congruent (or vice versa), either the target or the distractor is repeated (partial repetitions). It is known that partial repetitions require considerably more time than complete alternations or complete repetitions because in the first case two different event files must compete for the same feature, whereas in the latter cases two distinct event files are used (for an overview, see Henson, Eckstein, Waszak, Frings, \& Horner, 2014).

Particularly relevant in the present context is the observation that binding of stimulus and response features is weakened by negative affect (Colzato, Van Wouwe, \& Hommel, 
2007; for similar evidence regarding more sustained stimulusresponse binding, see Waszak \& Pholulamdeth, 2009). Therefore, some of the reviewed affective modulations of the sequential congruency effect could also reflect the interplay of binding and affect and not necessarily indicate an affective modulation of control. One way to address this problem would be to eliminate feature repetitions with confoundminimized task designs in which participants switch between two distinct stimulus-response sets (e.g., Dignath, Johannsen, Hommel, \& Kiesel, 2019; Duthoo, Abrahamse, Braem, Boehler, \& Notebaert, 2014; Kim \& Cho, 2014; Schmidt \& Weissman, 2014).

\section{Differentiating between conflict and errors}

For our discussion, we have used conflict-monitoring theory and assumed that errors and conflicts are comparable events (Yeung et al., 2004). It is parsimonious to assume that the affective nature of errors is a consequence of the underlying conflict. However, there are also arguments that error processing is not identical to conflict processing. First, there is evidence that errors activate brain areas, such as the amygdala (Koban, Pourtois, Vocat, \& Vuilleumier, 2010) or the anterior insula (Ullsperger, Harsay, Wessel, \& Ridderinkhof, 2010), in addition to the dACC. Source modeling has also revealed neural generators of the ERN response in the orbitofrontal cortex, suggesting that the neural substrate of error monitoring and conflict monitoring are not identical (Buzzell et al., 2017) and that activity in these regions could be responsible for the affective tagging of errors, but not of conflict (Koban \& Pourtois, 2014). Second, an influential theory of error processing explains the ERN response with a reward prediction error that is neurally implemented by the dopaminergic system (Holroyd \& Coles, 2002). This account can explain why the ERN is sensitive to manipulations of the monetary value of errors (in addition to manipulations of error expectancy; Ganushchak \& Schiller, 2008; Hajcak et al., 2005; Maier \& Steinhauser, 2013). Negative reward prediction errors could itself be viewed as aversive signals and could have caused some of the results described in the previous sections. Third, conscious awareness of errors is accompanied by the error positivity, a specific neural signature that can be differentiated from the ERN (Falkenstein et al., 1991). In theory, the error positivity can be explained in terms of evidence accumulation (Steinhauser \& Yeung, 2010) and has not been linked to conflict processing. Interestingly, several studies have shown a correlation between the size of the error positivity (but not the ERN) and the negativity of an error (as indicated by physiological measures of affect and arousal; see Elkins-Brown et al., 2016; Hajcak et al., 2003; O'Connell et al., 2007; Wessel, Danielmeier, \& Ullsperger, 2011). Thus, it remains possible that the negative affective consequences that follow after an error are not directly related to the ERN as suggested by the affect monitoring link.

\section{Summary}

The present article has reviewed evidence related to an affective extension of the conflict-monitoring theory. This affective-signaling hypothesis proposes (i) that conflict triggers negative affect, (ii) which is registered by a dedicated monitoring system and (iii) serves as a signal for control adaptation. On the basis of studies that have combined responseinterference tasks with affective measures, we conclude that (i) the conflict affect link is well supported by empirical evidence. Studies that have assessed affective influences on neural markers of performance monitoring have provided mostly correlational evidence in favor of (ii) the affect monitoring link, but the experimental evidence is ambiguous. Finally, studies that have probed affective influences on the sequential congruency effect have provided supporting evidence for (iii) the affect control link when considering tonic affect, whereas studies that have assessed influences of phasic affect on the sequential congruency effect have hd mixed implications. Therefore, from the present review we conclude that the affective-signaling hypothesis is supported by a substantial amount of evidence, but the review also points out areas that require more attention in order to develop a more comprehensive account of the interaction between affect and control.

\section{References}

Aarts, K., De Houwer, J., \& Pourtois, G. (2012). Evidence for the automatic evaluation of self-generated actions. Cognition, 124, 117-127. https://doi.org/10.1016/j.cognition.2012.05.009

Aarts, K., De Houwer, J., \& Pourtois, G. (2013). Erroneous and correct actions have a different affective valence: Evidence from ERPs. Emotion, 13, 960-973. https://doi.org/10.1037/a0032808

Abrahamse, E., \& Braem, S. (2015). Experience a conflict — either consciously or not (commentary on Desender, Van Opstal, and Van den Bussche, 2014). Frontiers in Psychology, 6, 179. https://doi.org/10. 3389/fpsyg.2015.00179

Abrahamse, E., Braem, S., Notebaert, W., \& Verguts, T. (2016). Grounding cognitive control in associative learning. Psychological Bulletin, 142, 693-728. https://doi.org/10.1037/bul0000047

Alexander, W. H., \& Brown, J. W. (2010). Computational models of performance monitoring and cognitive control. Topics in Cognitive Science, 2, 658-677.

Algom, D., Chajut, E., \& Lev, S. (2004). A rational look at the emotional stroop phenomenon: A generic slowdown, not a stroop effect. Journal of Experimental Psychology: General, 133, 323-338. https://doi.org/10.1037/0096-3445.133.3.323

Allport, A. (1987). Selection for action: Some behavioral and neurophysiological considerations of attention and action. In H. Heuer \& A. F. 
Sanders (Eds.), Perspectives on perception and action (pp. 395419). Hillsdale, NJ: Erlbaum.

Barrett, L. F., \& Russell, J. A. (1999). The structure of current affect: Controversies and emerging consensus. Current Directions in Psychological Science, 8, 10-14. https://doi.org/10.1111/14678721.00003

Becker, D., Jostmann, N. B., \& Holland, R. W. (2019). Adaptation in conflict: Are conflict-triggered control adjustments protected in the presence of motivational distractors? Cognition and Emotion, 33, 660-672. https://doi.org/10.1080/02699931.2018.1482825

Berkowitz, L., \& Harmon-Jones, E. (2004). Toward an understanding of the determinants of anger. Emotion, 4, 107-130.

Bernstein, P. S., Scheffers, M. K., \& Coles, M. G. H. (1995). "Where did I go wrong?" A psychophysiological analysis of error detection. Journal of Experimental Psychology: Human Perception and Performance, 21, 1312-1322. https://doi.org/10.1037/0096-1523. 21.6.1312

Böckler, A., Alpay, G., \& Stürmer, B. (2011). Accessory stimuli affect the emergence of conflict, not conflict control: A Simon-task ERP study. Experimental Psychology, 58, 102-109. https://doi.org/10. 1027/1618-3169/a000073

Boksem, M. A., Ruys, K. I., \& Aarts, H. (2011). Facing disapproval: Performance monitoring in a social context. Social Neuroscience, 6, 360-368

Booth, R. W., \& Peker, M. (2017). State anxiety impairs attentional control when other sources of control are minimal. Cognition and Emotion, 31, 1004-1011.

Botvinick, M. M. (2007). Conflict monitoring and decision making: Reconciling two perspectives on anterior cingulate function. Cognitive, Affective, \& Behavioral Neuroscience, 7, 356-366. https://doi.org/10.3758/CABN.7.4.356

Botvinick, M. M., Braver, T. S., Barch, D. M., Carter, C. S., \& Cohen, J. D. (2001). Conflict monitoring and cognitive control. Psychological Review, 108, 624-652. https://doi.org/10.1037/0033-295X.108.3. 624

Botvinick, M. M., Huffstetler, S., \& McGuire, J. T. (2009). Effort discounting in human nucleus accumbens. Cognitive, Affective, \& Behavioral Neuroscience, 9, 16-27. https://doi.org/10.3758/CABN. 9.1.16

Botvinick, M. M., Nystrom, L. E., Fissell, K., Carter, C. S., \& Cohen, J. D. (1999). Conflict monitoring versus selection-for-action in anterior cingulate cortex. Nature, 402, 179-181. https://doi.org/10.1038/ 46035

Botvinick, M. M., \& Rosen, Z. B. (2009). Anticipation of cognitive demand during decision-making. Psychological Research, 73, 835-842. https://doi.org/10.1007/s00426-008-0197-8

Braem, S., King, J. A., Korb, F. M., Krebs, R. M., Notebaert, W., \& Egner, T. (2013). Affective modulation of cognitive control is determined by performance-contingency and mediated by ventromedial prefrontal and cingulate cortex. Journal of Neuroscience, 33, 16961-16970.

Braem, S., King, J. A., Korb, F. M., Krebs, R. M., Notebaert, W., \& Egner, T. (2017). The role of anterior cingulate cortex in the affective evaluation of conflict. Journal of Cognitive Neuroscience, 29, 137149.

Braem, S., Verguts, T., Roggeman, C., \& Notebaert, W. (2012). Reward modulates adaptations to conflict. Cognition, 125, 324-332.

Brosch, T., Sander, D., Pourtois, G., \& Scherer, K. R. (2008). Beyond fear: Rapid spatial orienting toward positive emotional stimuli. Psychological Science, 19, 362-370.

Brouillet, T., Ferrier, L. P., Grosselin, A., \& Brouillet, D. (2011). Action compatibility effects are hedonically marked and have incidental consequences on affective judgment. Emotion, 11, 1202-1205. https://doi.org/10.1037/a0024742
Buttaccio, D. R., \& Hahn, S. (2010). The effect of behavioral response on affective evaluation. Acta Psychologica, 135, 343-348. https://doi. org/10.1016/j.actpsy.2010.09.004

Buzzell, G. A., Richards, J. E., White, L. K., Barker, T. V., Pine, D. S., \& Fox, N. A. (2017). Development of the error-monitoring system from ages 9-35: Unique insight provided by MRI-constrained source localization of EEG. NeuroImage, 157, 13-26.

Cannon, P. R., Hayes, A. E., \& Tipper, S. P. (2010). Sensorimotor fluency influences affect: Evidence from electromyography. Cognition and Emotion, 24, 681-691.

Cano Rodilla, C., Beauducel, A., \& Leue, A. (2016). Error-related negativity and the misattribution of state-anxiety following errors: On the reproducibility of Inzlicht and Al-Khindi (2012). Frontiers in Human Neuroscience, 10, 475. https://doi.org/10.3389/fnhum. 2016.00475

Carter, C. S., Braver, T. S., Barch, D. M., Botvinick, M. M., Noll, D., \& Cohen, J. D. (1998). Anterior cingulate cortex, error detection, and the online monitoring of performance. Science, 280, 747-749. https://doi.org/10.1126/science.280.5364.747

Cavanagh, J. F., \& Shackman, A. J. (2015). Frontal midline theta reflects anxiety and cognitive control: Meta-analytic evidence. Journal of Physiology, 109, 3-15.

Chelazzi, L., Perlato, A., Santandrea, E., \& Della Libera, C. (2013). Rewards teach visual selective attention. Vision Research, 85, 5872. https://doi.org/10.1016/j.visres.2012.12.005

Chetverikov, A., Iamschinina, P., Begler, A., Ivanchei, I., Filippova, M., \& Kuvaldina, M. (2017). Blame everyone: Error-related devaluation in Eriksen flanker task. Acta Psychologica, 180, 155-159.

Clawson, A., Clayson, P. E., \& Larson, M. J. (2013). Cognitive control adjustments and conflict adaptation in major depressive disorder. Psychophysiology, 50, 711-721.

Clayson, P. E., Clawson, A., \& Larson, M. J. (2011). Sex differences in electrophysiological indices of conflict monitoring. Biological Psychology, 87, 282-289. https://doi.org/10.1016/j.biopsycho. 2011.03.011

Codispoti, M., Bradley, M. M., \& Lang, P. J. (2001). Affective reactions to briefly presented pictures. Psychophysiology, 38, 474-478.

Colzato, L. S., Van Wouwe, N. C., \& Hommel, B. (2007). Feature binding and affect: Emotional modulation of visuo-motor integration. Neuropsychologia, 45, 440-446.

Cuthbert, B. N., Schupp, H. T., Bradley, M. M., Birbaumer, N., \& Lang, P. J. (2000). Brain potentials in affective picture processing: Covariation with autonomic arousal and affective report. Biological Psychology, 52, 95-111. https://doi.org/10.1016/S03010511(99)00044-7

Damasio, A. R. (1996). The somatic marker hypothesis and the possible functions of the prefrontal cortex. Philosophical Transactions of the Royal Society B, 351, 1413-1420.

Damen, T. G., Strick, M., Taris, T. W., \& Aarts, H. (2018). When conflict influences liking: The case of the Stroop task. PLoS ONE, 13, e0199700. https://doi.org/10.1371/journal.pone.0199700

Danielmeier, C., \& Ullsperger, M. (2011). Post-error adjustments. Frontiers in Psychology, 2, 233. https://doi.org/10.3389/fpsyg. 2011.00233

de Galan, M., Sellaro, R., Colzato, L. S., \& Hommel, B. (2014). Conflict adaptation is predicted by the cognitive, but not the affective alexithymia dimension. Frontiers in Psychology, 5, 768. https:// doi.org/10.3389/fpsyg.2014.00768

De Saedeleer, L., \& Pourtois, G. (2016). Evaluative priming reveals dissociable effects of cognitive versus physiological anxiety on action monitoring. Emotion, 16, 498.

Dehaene, S., Posner, M. I., \& Tucker, D. M. (1994). Localization of a neural system for error detection and compensation. Psychological Science, 5, 303-305. https://doi.org/10.1111/j.1467-9280.1994. tb00630.x 
Desender, K., Buc Calderon, C., Van Opstal, F., \& Van den Bussche, E. (2017). Avoiding the conflict: Metacognitive awareness drives the selection of low-demand contexts. Journal of Experimental Psychology: Human Perception and Performance, 43, 1397-1410. https://doi.org/10.1037/xhp0000391

di Pellegrino, G., Ciaramelli, E., \& Làdavas, E. (2007). The regulation of cognitive control following rostral anterior cingulate cortex lesion in humans. Journal of Cognitive Neuroscience, 19, 275-286. https:// doi.org/10.1162/jocn.2007.19.2.275

Dignath, D., \& Eder, A. B. (2015). Stimulus conflict triggers behavioral avoidance. Cognitive, Affective, \& Behavioral Neuroscience, 15, 822-836. https://doi.org/10.3758/s13415-015-0355-6

Dignath, D., Janczyk, M., \& Eder, A. B. (2017). Phasic valence and arousal do not influence post-conflict adjustments in the Simon task. Acta Psychologica, 174, 31-39.

Dignath, D., Johannsen, L., Hommel, B., \& Kiesel, A. (2019) Reconciling cognitive-control and episodic-retrieval accounts of sequential conflict modulation: Binding of control-states into eventfiles. Journal of Experimental Psychology: Human Perception and Performance, 45, 1265-1270. https://doi.org/10.1037/xhp0000673

Dignath, D., Kiesel, A., \& Eder, A. B. (2015). Flexible conflict management: Conflict avoidance and conflict adjustment in reactive cognitive control. Journal of Experimental Psychology: Learning, Memory, and Cognition, 41, 975-988. https://doi.org/10.1037/ $\mathrm{x} \operatorname{lm} 0000089$

Dimberg, U., Thunberg, M., \& Elmehed, K. (2000). Unconscious facial reactions to emotional facial expressions. Psychological Science, 11, 86-89.

Doallo, S., Raymond, J. E., Shapiro, K. L., Kiss, M., Eimer, M., \& Nobre, A. C. (2012). Response inhibition results in the emotional devaluation of faces: Neural correlates as revealed by fMRI. Social Cognitive and Affective Neuroscience, 7, 649-659. https://doi.org/ 10.1093/scan/nsr031

Dreisbach, G., \& Fischer, R. (2012). Conflicts as aversive signals. Brain and Cognition, 78, 94-98. https://doi.org/10.1016/j.bandc.2011.12. 003

Dreisbach, G., \& Fischer, R. (2015). Conflicts as aversive signals for control adaptation. Current Directions in Psychological Science, 24, 255-260. https://doi.org/10.1177/0963721415569569

Dreisbach, G., \& Fischer, R. (2016). Conflicts as aversive signals: Motivation for control adaptation in the service of affect regulation. In T. S. Braver (Ed.), Frontiers of cognitive psychology: Motivation and cognitive control (pp. 188-210). New York, NY, US: Routledge/Taylor \& Francis Group.

Dreisbach, G., Fröber, K., Berger, A., \& Fischer, R. (2019). Unexpected conflict signals loom larger in a positive context: Evidence from context specific control adjustments. Journal of Experimental Psychology: Learning, Memory, and Cognition, 45, 1398-1409. https://doi.org/10.1037/xlm0000662

Dreisbach, G., Reindl, A.-L., \& Fischer, R. (2016). Conflict and disfluency as aversive signals: Context-specific processing adjustments are modulated by affective location associations. Psychological Research, 82, 324-336.

Dunn, T. L., Gaspar, C., \& Risko, E. F. (2018). Cue awareness in avoiding effortful control. Neuropsychologia, 123, 77-91.

Duthoo, W., Abrahamse, E. L., Braem, S., Boehler, C. N., \& Notebaert, W. (2014). The congruency sequence effect 3.0: A critical test of conflict adaptation. PLoS One, 9, e110462. https://doi.org/10.1371/ journal.pone. 0110462

Eder, A. B., \& Dignath, D. (2014). I like to get nothing: Implicit and explicit evaluation of avoided negative outcomes. Journal of Experimental Psychology: Animal Learning and Cognition, 40, 55-62. https://doi.org/10.1037/xan0000005

Eder, A. B., \& Rothermund, K. (2010). Automatic influence of arousal information on evaluative processing: Valence-arousal interactions in an affective Simon task. Cognition and Emotion, 24, 1053-1061.
Egner, T., \& Hirsch, J. (2005). Cognitive control mechanisms resolve conflict through cortical amplification of task-relevant information. Nature Neuroscience, 8, 1784-1790. https://doi.org/10.1038/ nn1594

Egner, T., Jamieson, G., \& Gruzelier, J. (2005). Hypnosis decouples cognitive control from conflict monitoring processes of the frontal lobe. NeuroImage, 27, 969-978.

Eisenberger, N. I., Lieberman, M. D., \& Williams, K. D. (2003). Does rejection hurt? An fMRI study of social exclusion. Science, 302, 290-292.

Elkins-Brown, N., Saunders, B., He, F., \& Inzlicht, M. (2017). Stability and reliability of error-related electromyography over the corrugator supercilii with increasing trials. Psychophysiology, 54, 1559-1573.

Elkins-Brown, N., Saunders, B., \& Inzlicht, M. (2016). Error-related electromyographic activity over the corrugator supercilii is associated with neural performance monitoring. Psychophysiology, 53, 159170.

Elkins-Brown, N., Saunders, B., \& Inzlicht, M. (2018). The misattribution of emotions and the error-related negativity: A registered report. Cortex, 109, 124-140.

Endrass, T., \& Ullsperger, M. (2014). Specificity of performance monitoring changes in obsessive-compulsive disorder. Neuroscience \& Biobehavioral Reviews, 46, 124-138.

Etkin, A., Egner, T., Peraza, D. M., Kandel, E. R., \& Hirsch, J. (2006). Resolving emotional conflict: A role for the rostral anterior cingulate cortex in modulating activity in the amygdala. Neuron, 51, 871-882. https://doi.org/10.1016/j.neuron.2006.07.029

Falkenstein, M., Hohnsbein, J., Hoormann, J., \& Blanke, L. (1991). Effects of crossmodal divided attention on late ERP components: II. Error processing in choice reaction tasks. Electroencephalography and Clinical Neurophysiology, 78, 447455.

Falkenstein, M., Hoormann, J., Christ, S., \& Hohnsbein, J. (2000). ERP components on reaction errors and their functional significance: A tutorial. Biological Psychology, 51, 87-107. https://doi.org/10.1016/ S0301-051100031-9

Fazio, R. H., Sanbonmatsu, D. M., Powell, M. C., \& Kardes, F. R. (1986). On the automatic activation of attitudes. Journal of Personality and Social Psychology, 50, 229-238. https://doi.org/10.1037/00223514.50.2.229

Fellows, L. K., \& Farah, M. J. (2005). Is anterior cingulate cortex necessary for cognitive control? Brain, 128, 788-796.

Fenske, M. J., Raymond, J. E., Kessler, K., Westoby, N., \& Tipper, S. P. (2005). Attentional inhibition has social-emotional consequences for unfamiliar faces. Psychological Science, 16, 753-758. https:// doi.org/10.1111/j.1467-9280.2005.01609.x

Ferrey, A. E., Frischen, A., \& Fenske, M. J. (2012). Hot or not: Response inhibition reduces the hedonic value and motivational incentive of sexual stimuli. Frontiers in Psychology, 3, 575. https://doi.org/10. 3389/fpsyg.2012.00575

Fiehler, K., Ullsperger, M., Grigutsch, M., \& von Cramon, D. Y. (2004). Cardiac responses to error processing and response conflict. In Errors, conflicts, and the brain: Current opinions on performance monitoring (pp. 135-140). Leipzig, Germany: MPI for Human Cognitive and Brain Sciences.

Fischer, R., Plessow, F., Kunde, W., \& Kiesel, A. (2010). Trial-to-trial modulations of the Simon effect in conditions of attentional limitations: Evidence from dual tasks. Journal of Experimental Psychology: Human Perception and Performance, 36, 1576-1594. https://doi.org/10.1037/a0019326

Fischer, R., Ventura-Bort, C., Hamm, A., \& Weymar, M. (2018). Transcutaneous vagus nerve stimulation (tVNS) enhances conflicttriggered adjustment of cognitive control. Cognitive, Affective, \& Behavioral Neuroscience, 18, 680-693. https://doi.org/10.3758/ s13415-018-0596-2 
Foerster, A., Pfister, R., Reuss, H., \& Kunde, W. (2017). Commentary: Feeling the conflict: The crucial role of conflict experience in adaptation. Frontiers in Psychology, 8, 1405. https://doi.org/10.3389/ fpsyg.2017.01405

Forster, S. E., Carter, C. S., Cohen, J. D., \& Cho, R. Y. (2010). Parametric manipulation of the conflict signal and control-state adaptation. Journal of Cognitive Neuroscience, 23, 923-935. https://doi.org/ 10.1162/jocn.2010.21458

Frijda, N. H. (1988). The laws of emotion. American Psychologist, 43, 349-358. https://doi.org/10.1037/0003-066X.43.5.349

Frischen, A., Ferrey, A. E., Burt, D. H., Pistchik, M., \& Fenske, M. J. (2012). The affective consequences of cognitive inhibition: Devaluation or neutralization? Journal of Experimental Psychology: Human Perception and Performance, 38, 169-179. https://doi.org/10.1037/a0025981

Fritz, J., \& Dreisbach, G. (2013). Conflicts as aversive signals: Conflict priming increases negative judgments for neutral stimuli. Cognitive, Affective, \& Behavioral Neuroscience, 13, 311-317. https://doi.org/ 10.3758/s13415-012-0147-1

Fritz, J., \& Dreisbach, G. (2015). The time course of the aversive conflict signal. Experimental Psychology, 62, 30-39.

Fritz, J., Fischer, R., \& Dreisbach, G. (2015). The influence of negative stimulus features on conflict adaption: evidence from fluency of processing. Frontiers in Psychology, 6, 185. https://doi.org/10. 3389/fpsyg.2015.00185

Fröber, K., Stürmer, B., Frömer, R., \& Dreisbach, G. (2017). The role of affective evaluation in conflict adaptation: An LRP study. Brain and Cognition, 116, 9-16. https://doi.org/10.1016/j.bandc.2017.05.003

Ganushchak, L. Y., \& Schiller, N. O. (2008). Motivation and semantic context affect brain error-monitoring activity: An event-related brain potentials study. NeuroImage, 39, 395-405.

Gbadeyan, O., McMahon, K., Steinhauser, M., \& Meinzer, M. (2016). Stimulation of dorsolateral prefrontal cortex enhances adaptive cognitive control: A high-definition transcranial direct current stimulation study. Journal of Neuroscience, 36, 12530-12536. https://doi. org/10.1523/JNEUROSCI.2450-16.2016

Gehring, W. J., Coles, M. G. H., Meyer, D. E., \& Donchin, E. (1990). The error-related negativity: An event-related brain potential accompanying errors. Psychophysiology, 27, S34.

Gehring, W. J., Liu, Y., Orr, J. M., \& Carp, J. (2012). The error-related negativity (ERN/Ne). In E. S. Kappenman \& S. J. Luck (Eds.), The Oxford handbook of event-related potential components (pp. 231291). New York, NY: Oxford University Press.

Gehring, W. J., \& Willoughby, A. R. (2002). The medial frontal cortex and the rapid processing of monetary gains and losses. Science, 295, 2279-2282. https://doi.org/10.1126/science.1066893

Gold, A. L., Jarcho, J. M., Rosen, D. K., Pine, D. S., \& Ernst, M. (2015). Emotional and nonemotional conflict processing in pediatric and adult anxiety disorders. Journal of Child and Adolescent Psychopharmacology, 25, 754-763. https://doi.org/10.1089/cap. 2015.0066

Gold, J. M., Kool, W., Botvinick, M. M., Hubzin, L., August, S., \& Waltz, J. A. (2015). Cognitive effort avoidance and detection in people with schizophrenia. Cognitive, Affective, \& Behavioral Neuroscience, 15, $145-154$.

Goller, F., Khalid, S., \& Ansorge, U. (2017). A double dissociation between conscious and non-conscious priming of responses and affect: Evidence for a contribution of misattributions to the priming of affect. Frontiers in Psychology, 8, 453. https://doi.org/10.3389/ fpsyg.2017.00453

Goschke, T. (2000). Intentional reconfiguration and involuntary persistence in task set switching. In S. Monsell \& J. Driver (Eds.), Control of cognitive processes: Attention and performance XVIII (pp. 331355). Cambridge, MA: MIT Press.

Goschke, T., \& Bolte, A. (2014). Emotional modulation of control dilemmas: the role of positive affect, reward, and dopamine in cognitive stability and flexibility. Neuropsychologia, 62, 403-423. https://doi.org/10.1016/j.neuropsychologia.2014.07.015

Gratton, G., Coles, M. G. H., \& Donchin, E. (1992). Optimizing the use of information: Strategic control of activation of responses. Journal of Experimental Psychology: General, 121, 480-506. https://doi. org/10.1037/0096-3445.121.4.480

Hajcak, G., \& Foti, D. (2008). Errors are aversive: Defensive motivation and the error-related negativity. Psychological Science, 19, 103108. https://doi.org/10.1111/j.1467-9280.2008.02053.x

Hajcak, G., McDonald, N., \& Simons, R. F. (2003). To err is autonomic: Error-related brain potentials, ANS activity, and post-error compensatory behavior. Psychophysiology, 40, 895-903. https://doi.org/10. 1111/1469-8986.00107

Hajcak, G., McDonald, N., \& Simons, R. F. (2004). Error-related psychophysiology and negative affect. Brain and Cognition, 56, 189197. https://doi.org/10.1016/j.bandc.2003.11.001

Hajcak, G., Moser, J. S., Yeung, N., \& Simons, R. F. (2005). On the ERN and the significance of errors. Psychophysiology, 42, 151-160. https://doi.org/10.1111/j.1469-8986.2005.00270.x

Hatukai, T., \& Algom, D. (2017). The Stroop incongruity effect: Congruity relationship reaches beyond the Stroop task. Journal of Experimental Psychology: Human Perception and Performance, 43, 1098-1114. https://doi.org/10.1037/xhp0000381

Hengstler, M., Holland, R. W., van Steenbergen, H., \& van Knippenberg, A. (2014). The influence of approach-avoidance motivational orientation on conflict adaptation. Cognitive, Affective, \& Behavioral Neuroscience, 14, 548-560. https://doi.org/10.3758/s13415-0140295-6

Henson, R. N., Eckstein, D., Waszak, F., Frings, C., \& Horner, A. J. (2014). Stimulus-response bindings in priming. Trends in Cognitive Sciences, 18, 376-384. https://doi.org/10.1016/j.tics. 2014.03.004

Higgins, E. T. (1997). Beyond pleasure and pain. American Psychologist, $52,1280-1300$.

Hobson, N. M., Saunders, B., Al-Khindi, T., \& Inzlicht, M. (2014). Emotion down-regulation diminishes cognitive control: A neurophysiological investigation. Emotion, 14, 1014-1026. https://doi. org/10.1037/a0038028

Hochman, E. Y., Milman, V., \& Tal, L. (2017). Evidence for aversive withdrawal response to own errors. Acta Psychologica, 180, 147-154. https://doi.org/10.1016/j.actpsy. 2017.09.007

Holmes, A. J., \& Pizzagalli, D. A. (2007). Task feedback effects on conflict monitoring and executive control: Relationship to subclinical measures of depression. Emotion, 7, 68-76. https://doi.org/10. 1037/1528-3542.7.1.68

Holroyd, C. B., \& Coles, M. G. H. (2002). The neural basis of human error processing: Reinforcement learning, dopamine, and the errorrelated negativity. Psychological Review, 109, 679-709. https://doi. org/10.1037/0033-295X.109.4.679

Holroyd, C. B., Nieuwenhuis, S., Yeung, N., Nystrom, L., Mars, R. B., Coles, M. G. H., \& Cohen, J. D. (2004). Dorsal anterior cingulate cortex shows fMRI response to internal and external error signals. Nature Neuroscience, 7, 497-498.

Hommel, B., Proctor, R. W., \& Vu, K.-P. L. (2004). A feature-integration account of sequential effects in the Simon task. Psychological Research, 68, 1-17. https://doi.org/10.1007/s00426-003-0132-y

Inzlicht, M., \& Al-Khindi, T. (2012). ERN and the placebo: A misattribution approach to studying the arousal properties of the errorrelated negativity. Journal of Experimental Psychology: General, 141, 799-807. https://doi.org/10.1037/a0027586

Inzlicht, M., Bartholow, B. D., \& Hirsh, J. B. (2015). Emotional foundations of cognitive control. Trends in Cognitive Sciences, 19, 126 132.

Ivanchei, I., Begler, A., Iamschinina, P., Filippova, M., Kuvaldina, M., \& Chetverikov, A. (2018). A different kind of pain: affective valence of 
errors and incongruence. Cognition and Emotion, 33, 1051-1058. https://doi.org/10.1080/02699931.2018.1520077

Kanske, P., \& Kotz, S. A. (2010). Modulation of early conflict processing: N200 responses to emotional words in a flanker task. Neuropsychologia, 48, 3661-3664.

Kanske, P., \& Kotz, S. A. (2011a). Conflict processing is modulated by positive emotion: ERP data from a flanker task. Behavioural Brain Research, 219, 382-386.

Kanske, P., \& Kotz, S. A. (2011b). Emotion triggers executive attention: anterior cingulate cortex and amygdala responses to emotional words in a conflict task. Human Brain Mapping, 32, 198-208.

Kanske, P., \& Kotz, S. A. (2011c). Positive emotion speeds up conflict processing: ERP responses in an auditory Simon task. Biological Psychology, 87, 122-127.

Keil, J., Weisz, N., Paul-Jordanov, I., \& Wienbruch, C. (2010). Localization of the magnetic equivalent of the ERN and induced oscillatory brain activity. NeuroImage, 51, 404-411.

Kerns, J. G., Cohen, J. D., MacDonald, A. W., Cho, R. Y., Stenger, V. A., $\&$ Carter, C. S. (2004). Anterior cingulate conflict monitoring and adjustments in control. Science, 303, 1023-1026. https://doi.org/10. 1126/science. 1089910

Kiesel, A., Wendt, M., \& Peters, A. (2007). Task switching: On the origin of response congruency effects. Psychological Research, 71, 117125. https://doi.org/10.1007/s00426-005-0004-8

Kim, S., \& Cho, Y. S. (2014). Congruency sequence effect without feature integration and contingency learning. Acta Psychologica, 149, $60-68$.

Kiss, M., Raymond, J. E., Westoby, N., Nobre, A. C., \& Eimer, M. (2008). Response inhibition is linked to emotional devaluation: Behavioural and electrophysiological evidence. Frontiers in Human Neuroscience, 2, 13. https://doi.org/10.3389/neuro.09.013. 2008

Koban, L., \& Pourtois, G. (2014). Brain systems underlying the affective and social monitoring of actions: An integrative review. Neuroscience \& Biobehavioral Reviews, 46, 71-84. https://doi.org/ 10.1016/j.neubiorev.2014.02.014

Koban, L., Pourtois, G., Vocat, R., \& Vuilleumier, P. (2010). When your errors make me lose or win: Event-related potentials to observed errors of cooperators and competitors. Social Neuroscience, 5, $360-374$.

Kobayashi, N., Yoshino, A., Takahashi, Y., \& Nomura, S. (2007). Autonomic arousal in cognitive conflict resolution. Autonomic Neuroscience, 132, 70-75.

Kober, H., Barrett, L. F., Joseph, J., Bliss-Moreau, E., Lindquist, K., \& Wager, T. D. (2008). Functional grouping and cortical-subcortical interactions in emotion: A meta-analysis of neuroimaging studies. NeuroImage, 42, 998-1031. https://doi.org/10.1016/j.neuroimage. 2008.03.059

Kool, W., McGuire, J. T., Rosen, Z. B., \& Botvinick, M. M. (2010). Decision making and the avoidance of cognitive demand. Journal of Experimental Psychology: General, 139, 665-682. https://doi. org/10.1037/a0020198

Kool, W., McGuire, J. T., Wang, G. J., \& Botvinick, M. M. (2013). Neural and behavioral evidence for an intrinsic cost of self-control. PLoS ONE, 8, e 72626. https://doi.org/10.1371/journal.pone.0072626

Kopp, B., Rist, F., \& Mattler, U. (1996). N200 in the flanker task as a neurobehavioral tool for investigating executive control. Psychophysiology, 33, 282-294. https://doi.org/10.1111/j.14698986.1996.tb00425.x

Krug, M. K., \& Carter, C. S. (2010). Adding fear to conflict: A general purpose cognitive control network is modulated by trait anxiety. Cognitive, Affective, \& Behavioral Neuroscience, 10, 357-371.

Kuipers, M., Richter, M., Scheepers, D., Immink, M. A., Sjak-Shie, E., \& Van Steenbergen, H. (2017). How effortful is cognitive control? Insights from a novel method measuring single-trial evoked beta- adrenergic cardiac reactivity. International Journal of Psychophysiology, 119, 87-92.

Kunde, W., \& Wühr, P. (2006). Sequential modulations of correspondence effects across spatial dimensions and tasks. Memory \& Cognition, 34, 356-367. https://doi.org/10.3758/BF03193413

Kunishio, K., \& Haber, S. N. (1994). Primate cingulostriatal projection: Limbic striatal versus sensorimotor striatal input. Journal of Comparative Neurology, 350, 337-356.

Larsen, J. T., \& Norris, J. I. (2009a). A facial electromyographic investigation of affective contrast. Psychophysiology, 46, 831-842.

Larson, M. J., Clawson, A., Clayson, P. E., \& Baldwin, S. A. (2013). Cognitive conflict adaptation in generalized anxiety disorder. Biological Psychology, 94, 408-418.

Larson, M. J., Gray, A. C., Clayson, P. E., Jones, R., \& Kirwan, C. B. (2013). What are the influences of orthogonally-manipulated valence and arousal on performance monitoring processes? The effects of affective state. International Journal of Psychophysiology, 87, 327-339.

Larsen, J. T., \& Norris, J. I. (2009b). A facial electromyographic investigation of affective contrast. Psychophysiology, 46, 831-842. https:// doi.org/10.1111/j.1469-8986.2009.00820.x

Larson, M. J., Perlstein, W. M., Stigge-Kaufman, D., Kelly, K. G., \& Dotson, V. M. (2006). Affective context-induced modulation of the error-related negativity. NeuroReport, 17, 329-333.

Li, W., Jiang, Z., Liu, Y., Wu, Q., Zhou, Z., Jorgensen, N., . . Li, C. (2014). Positive and negative emotions modulate attention allocation in color-flanker task processing: Evidence from event related potentials. Motivation and Emotion, 38, 451-461.

Ligeza, T. S., \& Wyczesany, M. (2017). Cognitive conflict increases processing of negative, task-irrelevant stimuli. International Journal of Psychophysiology, 120, 126-135. https://doi.org/10. 1016/j.ijpsycho.2017.07.013

Lindström, B. R., Mattsson-Mårn, I. B., Golkar, A., \& Olsson, A. (2013). In your face: Risk of punishment enhances cognitive control and error-related activity in the corrugator supercilii muscle. PLoS ONE, 8, e65692. https://doi.org/10.1371/journal.pone.0065692

Liotti, M., Woldorff, M. G., Perez, R., \& Mayberg, H. S. (2000). An ERP study of the temporal course of the Stroop color-word interference effect. Neuropsychologia, 38, 701-711. https://doi.org/10.1016/ S0028-3932(99)00106-2

Liu, P., Yang, W., Chen, J., Huang, X., \& Chen, A. (2013). Alertness modulates conflict adaptation and feature integration in an opposite way. PLoS ONE, 8, e79146. https://doi.org/10.1371/journal.pone. 0079146

Luu, P., Collins, P., \& Tucker, D. M. (2000). Mood, personality, and selfmonitoring: Negative affect and emotionality in relation to frontal lobe mechanisms of error monitoring. Journal of Experimental Psychology: General, 129, 43-60. https://doi.org/10.1037/00963445.129.1.43

Luu, P., \& Pederson, S. M. (2004). The anterior cingulate cortex: Regulating actions in context. In M. I. Posner (Ed.), Cognitive neuroscience of attention (pp. 232-242). New York, NY: Guilford Press.

Maier, M. E., Scarpazza, C., Starita, F., Filogamo, R., \& Làdavas, E. (2016). Error monitoring is related to processing internal affective states. Cognitive, Affective, \& Behavioral Neuroscience, 16, 1050 1062. https://doi.org/10.3758/s13415-016-0452-1

Maier, M. E., \& Steinhauser, M. (2013). Updating expected action outcome in the medial frontal cortex involves an evaluation of error type. Journal of Neuroscience, 33, 15705-15709.

Martiny-Huenger, T., Gollwitzer, P. M., \& Oettingen, G. (2014). Selective attention to in- and out-group members systematically influences intergroup bias. Social Psychological and Personality Science, 5, 936-943. https://doi.org/10.1177/1948550614541296

Mayr, U., Awh, E., \& Laurey, P. (2003). Conflict adaptation effects in the absence of executive control. Nature Neuroscience, 6, 450-452. 
McGuire, J. T., \& Botvinick, M. M. (2010). Prefrontal cortex, cognitive control, and the registration of decision costs. Proceedings of the National Academy of Sciences, 107, 7922-7926. https://doi.org/10. 1073/pnas.0910662107

Metcalfe, J., \& Mischel, W. (1999). A hot/cool-system analysis of delay of gratification: Dynamics of willpower. Psychological Review, 106, 3-19. https://doi.org/10.1037/0033-295X.106.1.3

Meyer, A. (2017). A biomarker of anxiety in children and adolesequential congruency effectnts: A review focusing on the error-related negativity (ERN) and anxiety across development. Developmental Cognitive Neuroscience, 27, 58-68. https://doi.org/10.1016/j.dcn. 2017.08.001

Miller, E. K., \& Cohen, J. D. (2001). An integrative theory of prefrontal cortex function. Annual Review of Neuroscience, 24, 167-202. https://doi.org/10.1146/annurev.neuro.24.1.167

Miltner, W. H. R., Lemke, U., Weiss, T., Holroyd, C., Scheffers, M. K., \& Coles, M. G. H. (2003). Implementation of error-processing in the human anterior cingulate cortex: A source analysis of the magnetic equivalent of the error-related negativity. Biological Psychology, 64, 157-166. https://doi.org/10.1016/S0301-0511(03)00107-8

Morsella, E., Gray, J. R., Krieger, S. C., \& Bargh, J. A. (2009). The essence of conscious conflict: Subjective effects of sustaining incompatible intentions. Emotion, 9, 717-728. https://doi.org/10. 1037/a0017121

Moser, J. S., Hajcak, G., \& Simons, R. F. (2005). The effects of fear on performance monitoring and attentional allocation. Psychophysiology, 42, 261-268.

Moser, J., Moran, T., Schroder, H., Donnellan, B., \& Yeung, N. (2013). On the relationship between anxiety and error monitoring: A metaanalysis and conceptual framework. Frontiers in Human Neuroscience, 7, 466. https://doi.org/10.3389/fnhum.2013.00466

Moser, J. S., Most, S. B., \& Simons, R. F. (2010). Increasing negative emotions by reappraisal enhances subsequent cognitive control: A combined behavioral and electrophysiological study. Cognitive, Affective, \& Behavioral Neuroscience, 10, 195-207. https://doi. org/10.3758/CABN.10.2.195

Muraven, M., \& Baumeister, R. F. (2000). Self-regulation and depletion of limited resources: Does self-control resemble a muscle? Psychological Bulletin, 126, 247-259. https://doi.org/10.1037/ 0033-2909.126.2.247

Naccache, L., Dehaene, S., Cohen, L., Habert, M.-O., Guichart-Gomez, E., Galanaud, D., \& Willer, J.-C. (2005). Effortless control: Executive attention and conscious feeling of mental effort are dissociable. Neuropsychologia, 43, 1318-1328. https://doi.org/10. 1016/j.neuropsychologia.2004.11.024

Németh, G., Hegedüs, K., \& Molnâr, L. (1988). Akinetic mutism associated with bicingular lesions: Clinicopathological and functional anatomical correlates. European Archives of Psychiatry and Neurological Sciences, 237, 218-222.

Nieuwenhuis, S., Ridderinkhof, K. R., Blom, J., Band, G. P., \& Kok, A. (2001). Error-related brain potentials are differentially related to awareness of response errors: Evidence from an antisaccade task. Psychophysiology, 38, 752-760.

Nigbur, R., Schneider, J., Sommer, W., Dimigen, O., \& Stürmer, B. (2015). Ad-hoc and context-dependent adjustments of selective attention in conflict control: An ERP study with visual probes. NeuroImage, 107, 76-84. https://doi.org/10.1016/j.neuroimage. 2014.11.052

Nixon, E., Liddle, P. F., Nixon, N. L., \& Liotti, M. (2013). On the interaction between sad mood and cognitive control: The effect of induced sadness on electrophysiological modulations underlying Stroop conflict processing. International Journal of Psychophysiology, 87, 313-326. https://doi.org/10.1016/j.ijpsycho. 2012.11.014

Norman, D. A., \& Shallice, T. (1986). Attention to action: Willed and automatic control of behavior. In R. J. Davidson, G. E. Schwartz, \&
D. Shapiro (Eds.), Consciousness and self-regulation: Advances in research (Vol. 4, pp. 1-18). Berlin, Germany: Springer.

Notebaert, W., \& Verguts, T. (2008). Cognitive control acts locally. Cognition, 106, 1071-1080. https://doi.org/10.1016/j.cognition. 2007.04.011

O'Connell, R. G., Dockree, P. M., Bellgrove, M. A., Kelly, S. P., Hester, R., Garavan, H., \& Foxe, J. J. (2007). The role of cingulate cortex in the detection of errors with and without awareness: a high-density electrical mapping study. European Journal of Neuroscience, 25, 2571-2579.

Oatley, K., \& Johnson-Laird, P. N. (1987). Towards a cognitive theory of emotions. Cognition and Emotion, 1, 29-50. https://doi.org/10. 1080/02699938708408362

Okon-Singer, H., Hendler, T., Pessoa, L., \& Shackman, A. J. (2015). The neurobiology of emotion-cognition interactions: Fundamental questions and strategies for future research. Frontiers in Human Neuroscience, 9, 58. https://doi.org/10.3389/fnhum.2015.00058

Olvet, D. M., \& Hajcak, G. (2011). The error-related negativity relates to sadness following mood induction among individuals with high neuroticism. Social Cognitive and Affective Neuroscience, 7, 289295.

Osinsky, R., Alexander, N., Gebhardt, H., \& Hennig, J. (2010). Trait anxiety and dynamic adjustments in conflict processing. Cognitive, Affective, \& Behavioral Neuroscience, 10, 372-381. https://doi.org/ 10.3758/CABN.10.3.372

Osinsky, R., Gebhardt, H., Alexander, N., \& Hennig, J. (2012). Trait anxiety and the dynamics of attentional control. Biological Psychology, 89, 252-259.

Otten, M., \& Jonas, K. J. (2014). Humiliation as an intense emotional experience: Evidence from the electro-encephalogram. Social Neuroscience, 9, 23-35

Padmala, S., Bauer, A., \& Pessoa, L. (2011). Negative emotion impairs conflict-driven executive control. Frontiers in Psychology, 2, 192. https://doi.org/10.3389/fpsyg.2011.00192

Pailing, P. E., Segalowitz, S. J., Dywan, J., \& Davies, P. L. (2002). Error negativity and response control. Psychophysiology, 39, 198-206.

Pan, F., Shi, L., Lu, Q., Wu, X., Xue, S., \& Li, Q. (2016). The negative priming effect in cognitive conflict processing. Neuroscience Letters, 628, 35-39.

Papez, J. W. (1937). A proposed mechanism of emotion. Archives of Neurology \& Psychiatry, 38, 725-743. https://doi.org/10.1001/ archneurpsyc.1937.02260220069003

Paul, K., Walentowska, W., Bakic, J., Dondaine, T., \& Pourtois, G. (2017). Modulatory effects of happy mood on performance monitoring: Insights from error-related brain potentials. Cognitive, Affective, \& Behavioral Neuroscience, 17, 106-123.

Payne, B. K., Cheng, C. M., Govorun, O., \& Stewart, B. D. (2005). An inkblot for attitudes: Affect misattribution as implicit measurement. Journal of Personality and Social Psychology, 89, 277-293. https:// doi.org/10.1037/0022-3514.89.3.277

Pessoa, L. (2008). On the relationship between emotion and cognition. Nature Reviews Neuroscience, 9, 148-158. https://doi.org/10.1038/ $\operatorname{nrn} 2317$

Pfabigan, D. M., Pintzinger, N. M., Siedek, D. R., Lamm, C., Derntl, B., \& Sailer, U. (2013). Feelings of helplessness increase ERN amplitudes in healthyindividuals. Neuropsychologia, 51, 613-621. https:// doi.org/10.1016/j.neuropsychologia.2012.12.008

Pourtois, G., Vocat, R., N'Diaye, K., Spinelli, L., Seeck, M., \& Vuilleumier, P. (2010). Errors recruit both cognitive and emotional monitoring systems: Simultaneous intracranial recordings in the dorsal anterior cingulate gyrus and amygdala combined with fMRI. Neuropsychologia, 48, 1144-1159. https://doi.org/10.1016/j. neuropsychologia.2009.12.020

Rainville, P., Duncan, G. H., Price, D. D., Carrier, B., \& Bushnell, M. C. (1997). Pain affect encoded in human anterior cingulate but not 
somatosensory cortex. Science, 277, 968-971. https://doi.org/10. 1126/science.277.5328.968

Randles, D., Kam, J. W., Heine, S. J., Inzlicht, M., \& Handy, T. C. (2016). Acetaminophen attenuates error evaluation in cortex. Social Cognitive and Affective Neuroscience, 11, 899-906.

Regenberg, N. F. E., Häfner, M., \& Semin, G. R. (2012). The groove move. Experimental Psychology, 59, 30-37. https://doi.org/10. 1027/1618-3169/a000122

Reinhart, R. M. G., \& Woodman, G. F. (2014). Causal control of medialfrontal cortex governs electrophysiological and behavioral indices of performance monitoring and learning. Journal of Neuroscience, 34 , 4214-4227. https://doi.org/10.1523/JNEUROSCI.5421-13.2014

Renaud, P., \& Blondin, J.-P. (1997). The stress of Stroop performance: Physiological and emotional responses to color-word interference, task pacing, and pacing speed. International Journal of Psychophysiology, 27, 87-97. https://doi.org/10.1016/S01678760(97)00049-4

Ridderinkhof, K. R., Ullsperger, M., Crone, E. A., \& Nieuwenhuis, S. (2004). The role of the medial frontal cortex in cognitive control. Science, 306, 443-447.

Riesel, A., Weinberg, A., Moran, T., \& Hajcak, G. (2013). Time course of error-potentiated startle and its relationship to error-related brain activity. Journal of Psychophysiology, 27, 51-59. https://doi.org/ 10.1027/0269-8803/a000093

Robinson, M. D., Storbeck, J., Meier, B. P., \& Kirkeby, B. S. (2004). Watch out! That could be dangerous: Valence-arousal interactions in evaluative processing. Personality and Social Psychology Bulletin, 30, 1472-1484.

Roh, D., Chang, J.-G., \& Kim, C.-H. (2016). Emotional interference modulates performance monitoring in patients with obsessivecompulsive disorder. Progress in Neuro-Psychopharmacology and Biological Psychiatry, 68, 44-51.

Saunders, B., Lin, H., Milyavskaya, M., \& Inzlicht, M. (2017). The emotive nature of conflict monitoring in the medial prefrontal cortex. International Journal of Psychophysiology, 119, 31-40.

Saunders, B., Riesel, A., Klawohn, J., \& Inzlicht, M. (2018). Interpersonal touch enhances cognitive control: A neurophysiological investigation. Journal of Experimental Psychology: General, 147, 1066-1077. https://doi.org/10.1037/xge0000412

Sayalı, C., \& Badre, D. (2019). Neural systems of cognitive demand avoidance. Neuropsychologia, 123, 41-54.

Schacht, A., Dimigen, O., \& Sommer, W. (2010). Emotions in cognitive conflicts are not aversive but are task specific. Cognitive, Affective, \& Behavioral Neuroscience, 10, 349-356. https://doi.org/10.3758/ CABN.10.3.349

Schacht, A., Nigbur, R., \& Sommer, W. (2009). Emotions in Go/NoGo conflicts. Psychological Research, 73, 843-856. https://doi.org/10. 1007/s00426-008-0192-0

Scherer, K. R., \& Moors, A. (2019). The emotion process: Event appraisal and component differentiation. Annual Review of Psychology, 70, 719-745.

Schmidt, J. R., \& Weissman, D. H. (2014). Congruency sequence effects without feature integration or contingency learning confounds. PLoS ONE, 9, e102337. https://doi.org/10.1371/journal.pone. 0102337

Schouppe, N., Braem, S., De Houwer, J., Silvetti, M., Verguts, T., Ridderinkhof, K. R., \& Notebaert, W. (2015). No pain, no gain: The affective valence of congruency conditions changes following a successful response. Cognitive, Affective, \& Behavioral Neuroscience, 15, 251-261. https://doi.org/10.3758/s13415-0140318-3
Schouppe, N., De Houwer, J., Ridderinkhof, K. R., \& Notebaert, W. (2012). Conflict: Run! Reduced Stroop interference with avoidance responses. Quarterly Journal of Experimental Psychology, 65, $1052-1058$.

Schouppe, N., Ridderinkhof, K. R., Verguts, T., \& Notebaert, W. (2014). Context-specific control and context selection in conflict tasks. Acta Psychologica, 146, 63-66.

Schuch, S., Dignath, D., Steinhauser, M., \& Janczyk, M. (2019). Monitoring and control in multitasking. Psychonomic Bulletin \& Review, 26, 222-240. https://doi.org/10.3758/s13423-018-1512-z

Schuch, S., \& Koch, I. (2015). Mood states influence cognitive control: The case of conflict adaptation. Psychological Research, 79, 759-772.

Schuch, S., \& Pütz, S. (2018). Mood state dissociates conflict adaptation within tasks and across tasks. Journal of Experimental Psychology: Learning, Memory, and Cognition, 44, 1487-1499. https://doi.org/ $10.1037 / x \operatorname{lm} 0000530$.

Schuch, S., Zweerings, J., Hirsch, P., \& Koch, I. (2017). Conflict adaptation in positive and negative mood: Applying a success-failure manipulation. Acta Psychologica, 176, 11-22.

Schupp, H. T., Lutzenberger, W., Rau, H., \& Birbaumer, N. (1994). Positive shifts of event-related potentials: a state of cortical disfacilitation as reflected by the startle reflex probe. Electroencephalography and Clinical Neurophysiology, 90, 135144. https://doi.org/10.1016/0013-469490005-1

Senderecka, M. (2016). Threatening visual stimuli influence response inhibition and error monitoring: An event-related potential study. Biological Psychology, 113, 24-36.

Shackman, A. J., Salomons, T. V., Slagter, H. A., Fox, A. S., Winter, J. J., \& Davidson, R. J. (2011). The integration of negative affect, pain and cognitive control in the cingulate cortex. Nature Reviews Neuroscience, 12, 154-167. https://doi.org/10.1038/nrn2994

Smith, J. L., Smith, E. A., Provost, A. L., \& Heathcote, A. (2010). Sequence effects support the conflict theory of N2 and P3 in the Go/NoGo task. International Journal of Psychophysiology, 75, 217-226.

Soutschek, A., Müller, H. J., \& Schubert, T. (2013). Conflict-specific effects of accessory stimuli on cognitive control in the Stroop task and the Simon task. Experimental Psychology, 60, 140-148. https:// doi.org/10.1027/1618-3169/a000181

Spruit, I. M., Wilderjans, T. F., \& van Steenbergen, H. (2018). Heart work after errors: Behavioral adjustment following error commission involves cardiac effort. Cognitive, Affective, \& Behavioral Neuroscience, 18, 375-388. https://doi.org/10.3758/s13415-0180576-6

Spunt, R. P., Lieberman, M. D., Cohen, J. R., \& Eisenberger, N. I. (2012). The phenomenology of error processing: The dorsal ACC response to stop-signal errors tracks reports of negative affect. Journal of Cognitive Neuroscience, 24, 1753-1765.

Steinhauser, M., Ernst, B., \& Ibald, K. W. (2017). Isolating component processes of posterror slowing with the psychological refractory period paradigm. Journal of Experimental Psychology: Learning, Memory, and Cognition, 43, 653-659. https://doi.org/10.1037/ $\mathrm{x} \operatorname{lm} 0000329$

Steinhauser, M., Flaisch, T., Meinzer, M., \& Schupp, H. T. (2016). Cognitive control modulates preferential sensory processing of affective stimuli. Neuropsychologia, 91, 435-443.

Steinhauser, M., \& Yeung, N. (2010). Decision processes in human performance monitoring. Journal of Neuroscience, 30, 15643-15653. https://doi.org/10.1523/JNEUROSCI.1899-10.2010

Strack, F., \& Deutsch, R. (2004). Reflective and impulsive determinants of social behavior. Personality and Social Psychology Review, 8, $220-247$ 
Stürmer, B., Leuthold, H., Soetens, E., Schröter, H., \& Sommer, W. (2002). Control over location-based response activation in the Simon task: Behavioral and electrophysiological evidence. Journal of Experimental Psychology: Human Perception and Performance, 28, 1345-1363. https://doi.org/10.1037/0096-1523.28.6.1345

Stürmer, B., Nigbur, R., Schacht, A., \& Sommer, W. (2011). Reward and punishment effects on error processing and conflict control. Frontiers in Psychology, 2, 335. https://doi.org/10.3389/fpsyg. 2011.00335

Stürmer, B., Redlich, M., Irlbacher, K., \& Brandt, S. (2007). Executive control over response priming and conflict: A transcranial magnetic stimulation study. Experimental Brain Research, 183, 329-339. https://doi.org/10.1007/s00221-007-1053-6

Themanson, J. R., Ball, A. B., Khatcherian, S. M., \& Rosen, P. J. (2014). The effects of social exclusion on the ERN and the cognitive control of action monitoring. Psychophysiology, 51, 215-225.

Tolomeo, S., Christmas, D., Jentzsch, I., Johnston, B., Sprengelmeyer, R., Matthews, K., \& Steele, J. D. (2016). A causal role for the anterior mid-cingulate cortex in negative affect and cognitive control. Brain, 139, 1844-1854. https://doi.org/10.1093/brain/aww069

Ullsperger, M., Harsay, H. A., Wessel, J. R., \& Ridderinkhof, K. R. (2010). Conscious perception of errors and its relation to the anterior insula. Brain Structure and Function, 214, 629-643. https://doi.org/ 10.1007/s00429-010-0261-1

van der Veen, F. M., van der Molen, M. W., \& Jennings, J. R. (2000). Selective inhibition is indexed by heart rate slowing. Psychophysiology, 37, 607-613. https://doi.org/10.1111/14698986.3750607

van der Wel, P., \& van Steenbergen, H. (2018). Pupil dilation as an index of effort in cognitive control tasks: A review. Psychonomic Bulletin \& Review, 25, 2005-2015. https://doi.org/10.3758/s13423-0181432-y

van Steenbergen, H. (2015). Affective modulation of cognitive control: A biobehavioral perspective. In G. Gendolla, M. Tops, \& S. Koole (Eds.), Handbook of biobehavioral approaches to self-regulation (pp. 89-107). Berlin, Germany: Springer.

van Steenbergen, H., Band, G. P. H., \& Hommel, B. (2009). Reward counteracts conflict adaptation: Evidence for a role of affect in executive control. Psychological Science, 20, 1473-1477. https://doi. org/10.1111/j.1467-9280.2009.02470.x

van Steenbergen, H., Band, G. P., \& Hommel, B. (2010). In the mood for adaptation: How affect regulates conflict-driven control. Psychological Science, 21, 1629-1634.

van Steenbergen, H., Band, G. P., Hommel, B., Rombouts, S. A., \& Nieuwenhuis, S. (2015). Hedonic hotspots regulate cingulatedriven adaptation to cognitive demands. Cerebral Cortex, 25, 1746-1756. https://doi.org/10.1093/cercor/bht416

van Steenbergen, H., Booij, L., Band, G. P., Hommel, B., \& van der Does, A. W. (2012). Affective regulation of cognitive-control adjustments in remitted depressive patients after acute tryptophan depletion. Cognitive, Affective, \& Behavioral Neuroscience, 12, 280-286.

Vendrell, P., Junqué, C., Pujol, J., Jurado, M. A., Molet, J., \& Grafman, J. (1995). The role of prefrontal regions in the Stroop task. Neuropsychologia, 33, 341-352.

Verguts, T., \& Notebaert, W. (2009). Adaptation by binding: A learning account of cognitive control. Trends in Cognitive Sciences, 13, 252257.

Vermeylen, L., Braem, S., \& Notebaert, W. (2019). The affective twitches of task switches: Task switch cues are evaluated as negative. Cognition, 183, 124-130.
Vogt, J., Lozo, L., Koster, E. H., \& De Houwer, J. (2011). On the role of goal relevance in emotional attention: Disgust evokes early attention to cleanliness. Cognition and Emotion, 25, 466-477.

Waid, W. M., \& Orne, M. T. (1982). Reduced electrodermal response to conflict, failure to inhibit dominant behaviors, and delinquency proneness. Journal of Personality and Social Psychology, 43, 769-774. https://doi.org/10.1037/0022-3514.43.4.769

Wang, X., Zhao, X., Xue, G., \& Chen, A. (2016). Alertness function of thalamus in conflict adaptation. NeuroImage, 132, 274-282.

Wang, Y., Yang, L., \& Wang, Y. (2014). Suppression (but not reappraisal) impairs subsequent error detection: An ERP study of emotion regulation's resource-depleting effect. PLoS ONE, 9, e96339. https://doi. org/10.1371/journal.pone.0096339

Waszak, F., \& Pholulamdeth, V. (2009). Episodic S-R bindings and emotion: About the influence of positive and negative action effects on stimulus-response associations. Experimental Brain Research, 194, 489-494.

Weinberg, A., Dieterich, R., \& Riesel, A. (2015). Error-related brain activity in the age of RDoC: A review of the literature. International Journal of Psychophysiology, 98, 276-299.

Wendt, M., Kiesel, A., Geringswald, F., Purmann, S., \& Fischer, R. (2014). Attentional adjustment to conflict strength: Evidence from the effects of manipulating flanker-target SOA on response times and prestimulus pupil size. Experimental Psychology, 61, 55-67. https://doi.org/10.1027/1618-3169/a000227

Wentura, D., Müller, P., \& Rothermund, K. (2014). Attentional capture by evaluative stimuli: Gain-and loss-connoting colors boost the additional-singleton effect. Psychonomic Bulletin \& Review, 21, 701-707.

Wessel, J. R., Danielmeier, C., \& Ullsperger, M. (2011). Error awareness revisited: Accumulation of multimodal evidence from central and autonomic nervous systems. Journal of Cognitive Neuroscience, 23, 3021-3036.

West, R., Choi, P., \& Travers, S. (2010). The influence of negative affect on the neural correlates of cognitive control. International Journal of Psychophysiology, 76, 107-117.

Wiswede, D., Münte, T. F., Goschke, T., \& Rüsseler, J. (2009). Modulation of the error-related negativity by induction of shortterm negative affect. Neuropsychologia, 47, 83-90.

Wiswede, D., Münte, T. F., Krämer, U. M., \& Rüsseler, J. (2009). Embodied emotion modulates neural signature of performance monitoring. PLoS ONE, 4, e5754. https://doi.org/10.1371/journal.pone. 0005754

Wiswede, D., Münte, T. F., \& Rüsseler, J. (2009). Negative affect induced by derogatory verbal feedback modulates the neural signature of error detection. Social Cognitive and Affective Neuroscience, 4, 227-237.

Xue, S., Cui, J., Wang, K., Zhang, S., Qiu, J., \& Luo, Y. (2013). Positive emotion modulates cognitive control: An event-related potentials study. Scandinavian Journal of Psychology, 54, 82-88.

Yamaguchi, M., \& Nishimura, A. (2019). Modulating proactive cognitive control by reward: Differential anticipatory effects of performancecontingent and non-contingent rewards. Psychological Research, 83, 258-274. https://doi.org/10.1007/s00426-018-1027-2

Yang, Q., \& Pourtois, G. (2018). Conflict-driven adaptive control is enhanced by integral negative emotion on a short time scale. Cognition and Emotion, 32, 1637-1653. https://doi.org/10.1080/02699931

Yeung, N., Botvinick, M. M., \& Cohen, J. D. (2004). The neural basis of error detection: Conflict monitoring and the error-related negativity. Psychological Review, 111, 931-959. https://doi.org/10.1037/0033295X.111.4.931 
Yuan, J., Xu, S., Yang, J., Liu, Q., Chen, A., Zhu, L., . . Li, H. (2011). Pleasant mood intensifies brain processing of cognitive control: ERP correlates. Biological Psychology, 87, 17-24.

Zeng, Q., Qi, S., Li, M., Yao, S., Ding, C., \& Yang, D. (2017). Enhanced conflict-driven cognitive control by emotional arousal, not by valence. Cognition and Emotion, 31, 1083-1096.

Zhang, J., Kiesel, A., \& Dignath, D. (2019). Affective influence on context-specific proportion congruent (CSPC) effect: Neutral or affective facial expressions as context stimuli. Experimental Psychology, 66, 86-97. https://doi.org/10.1027/1618-3169/a000436
Zhang, J., Teo, T., \& Wu, C. (2018). Emotion words modulate early conflict processing in a flanker task: Differentiating emotion-label words and emotion-laden words in second language. Language and Speech, 62, 641-651. https://doi.org/10.1177/0023830918807509

Zhao, X., Jia, L., \& Maes, J. H. (2018). Effect of achievement motivation on cognitive control adaptations. Journal of Cognitive Psychology, $30,453-465$.

Publisher's note Springer Nature remains neutral with regard to jurisdictional claims in published maps and institutional affiliations. 